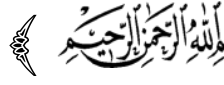

鼻

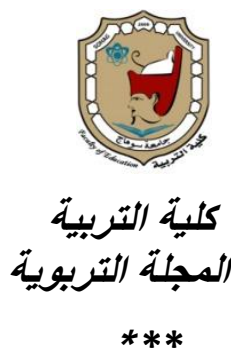

البمود الفكري (الدوجماتية) وملاقتهه باضطراب الشخصية الهدية لدى طلاب المرحلة الثانوية بمحافظة قلهة

$$
\text { | - (اعداد }
$$

أ - اعيد مساعل سعيد الزهراني

باحث ماجستير في الإرشاد النفسي

$$
\text { المجلة التربوية.العدد السابع والخمسون.يناير 19.19م }
$$

Print:(ISSN 1687-2649) Online:(ISSN 2536-9091) 


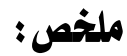

هافت الاراسة إلى الكثف عن درجة كل من الجمود الفكري (الدوجماتية)، وأعراض اضطراب

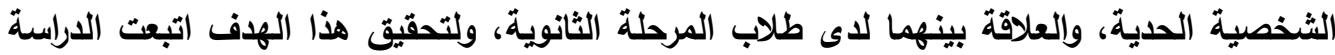
المنهج الوصفي بصورته الارتباطية، حيث تم التحقى من صدق وثبات مقياس الجمود الفكري

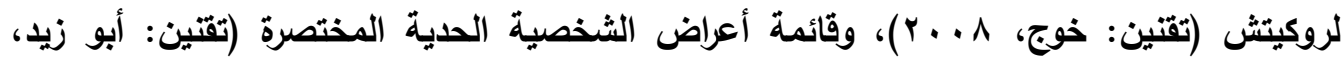

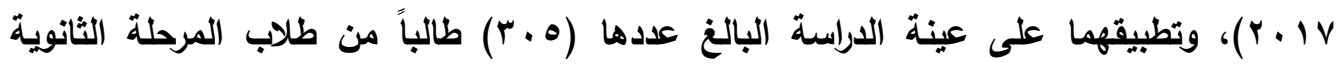

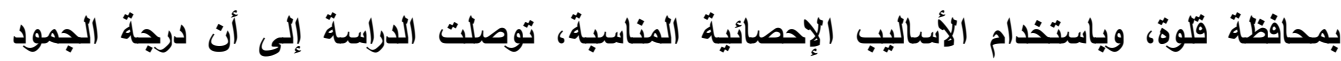

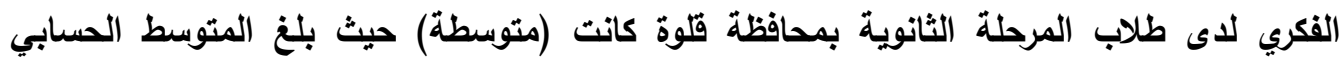

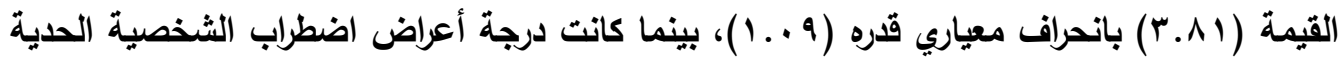

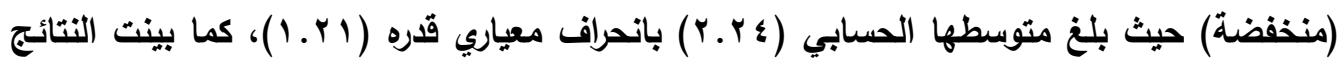

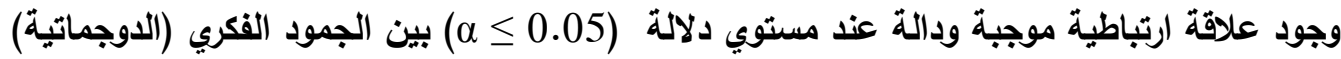

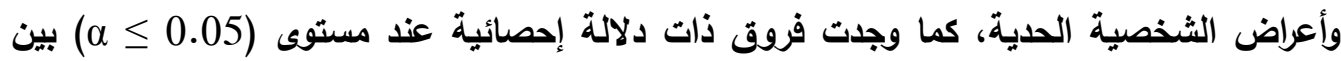
مرتفعي ومنخفي الجمود الفكري في أعراض اضطراب الثخصية الحدية لصالح مرتفعي الجمود الفكري، كما يمكن التنبؤ بدرجة أعراض الثخصية الحدية من خلال الجمود الفكري (الأبعاد والدرجة

The study aimed to identify the degree of dogmatism and its relation to borderline personality disorder among secondary school students in Qalwa governorate. To achieve this goal, the study followed the descriptive method in its correlative form. The validity and consistency of the measure were verified: the scale of Rochic's dogmatism (codification: Khoj, 2008)\& the list of the symptoms of the borderline personality disorder (codification: Abu Zeid, 2017), and applied to the sample of the study (305) students from secondary school in the province of Qalw. Using the appropriate statistical methods, the study found that the level of intellectual immobility among secondary school students in Qalwa governorate was (medium) with mean 3.81 and standard deviation of 1.09 , while the symptoms of borderline personality disorder were low with mean 2.24, and standard deviation of 1.21, the results also showed a positive correlation and function at the level ) $\alpha \leq 0.05$ ( between dogmatism and borderline personality disorder, thus there were statistically significant differences at the level) $\alpha \leq 0.05$ ( between high and low dogmatism in the symptoms of borderline personality disorder in favor of high dogmatism, And the degree of borderline personality disorder symptoms can be predicted through dogmatism (dimensions and total degree. 


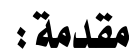

يمثل طلاب المرحلة الثانوية العامة فئة مهمة من فئات المجتمع، وتمر هذه الفئة بمرحلة المراهقة؛ والتي تثهر العايد من الاضطرابات؛ التي منشاؤها أفكارهم وتصوراتهم

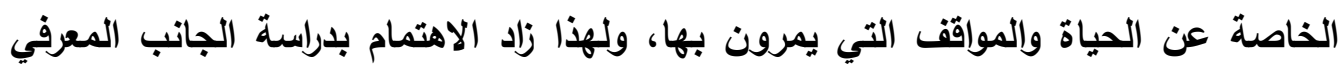
وأهيته في فهم شخصية المراهقين.

ومن وجهة نظر معرفية، فإن هناك اتفاق - إلى حد كبير - بين الباحثين والمهتمين بدراسة الأساليب المعرفية على أن هذه الأساليب تُعتبر بمثابة تكوينات نفسية تنمو مع نمو الفي الثخصية، وتفسر ما قد تمر به هذه الثخصية من اضطراب، فهي تعبر عن الطريقة الأكثر تفضيلاً في تنظيم ما يمارسه الثخص من نثاط معرفي في أبعاده المختلفة، وتهتم بالطريقة

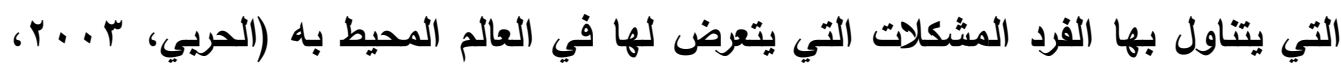

ومن هذه الأساليب المعرفية ما قدمه روكيتش (Rokeach) في نظريته المُسماة

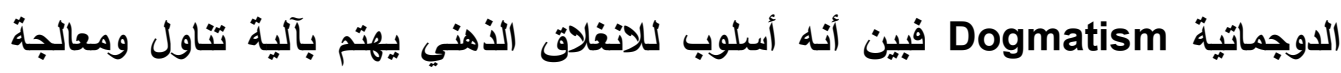

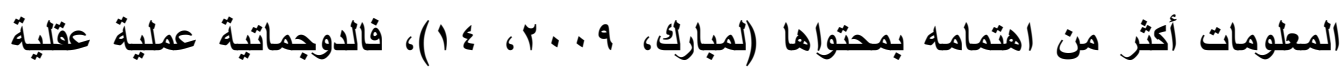

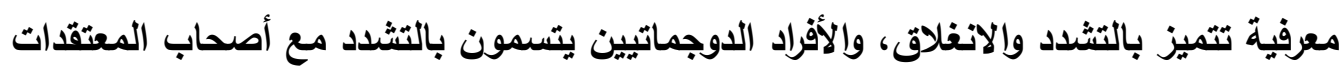

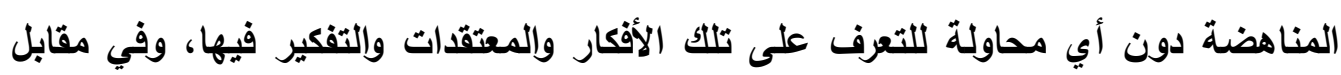

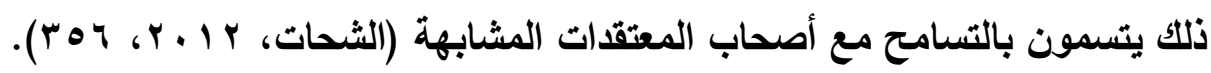

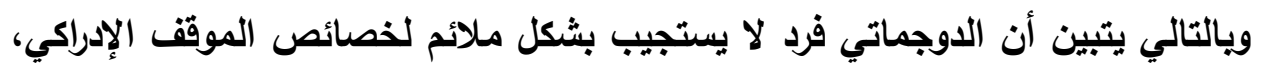

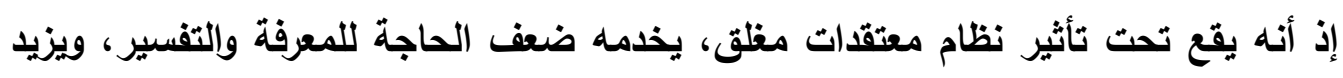

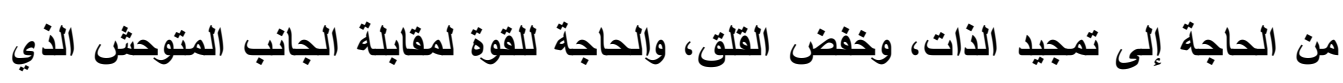

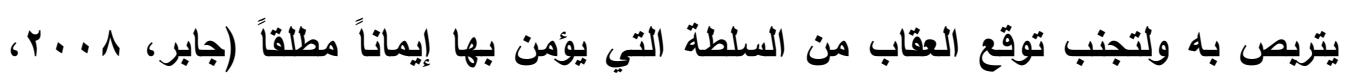
(YTV

وفي هذا الثأن تذكر دراسة فيراندو وفابيا ويوريانو (Ferrando, Fabia\& Urbano, 2016, 332)

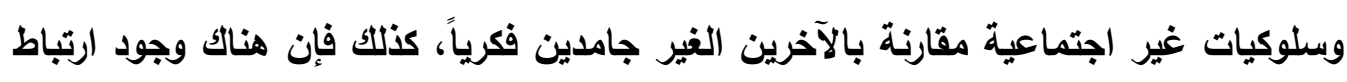


موجب بين الجمود الفكري والعدوانية، كما أن الدوجماتيين هم أكثر الناس غضباً وعدوانية مقارنة بيقية الفئات.

وما سبق يكثف عن مؤثرات أو دلائل تبين إمكانية حدوث اضطراب في الثخصية

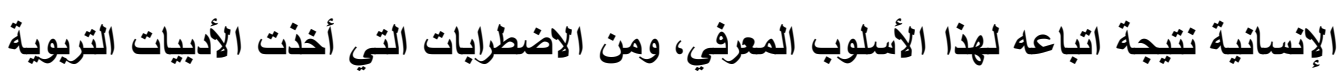

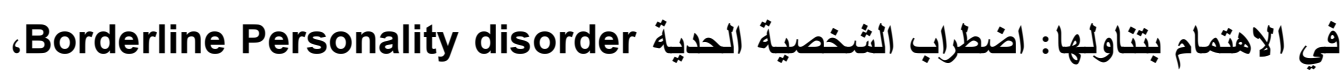

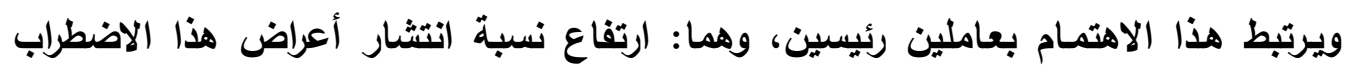

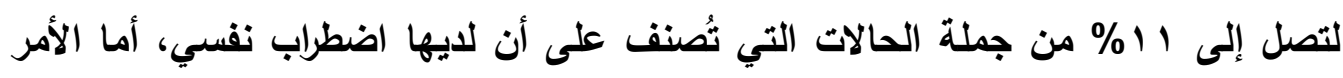

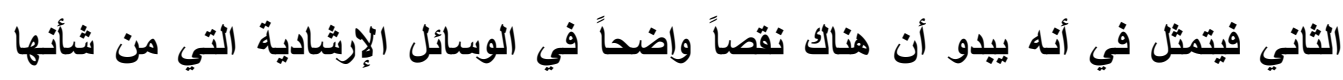

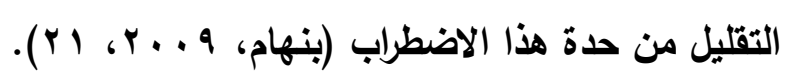

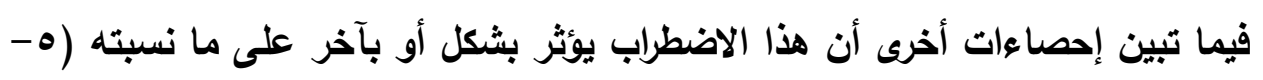

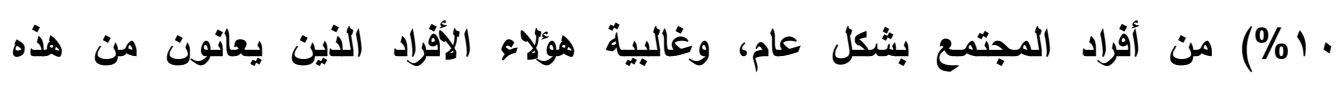

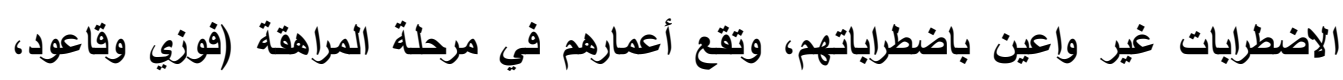

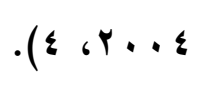

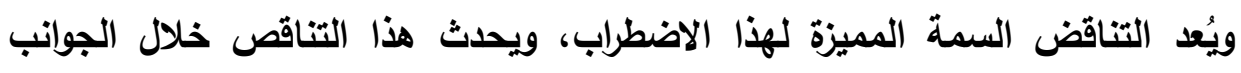

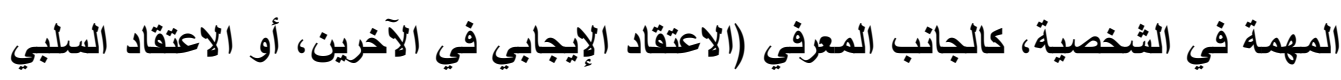

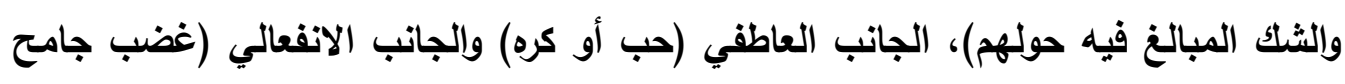

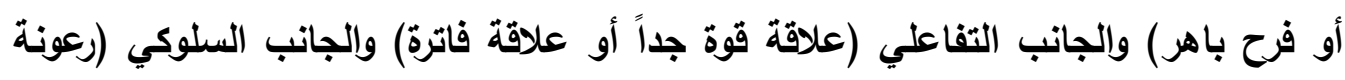

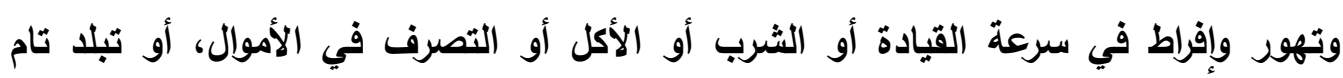

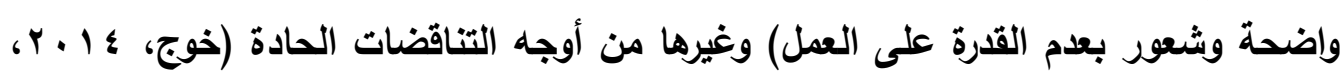
.$(1.9$

ومع استهاف فئة المراهقين - بداية من طلاب المرحلة الثانوية وما بعدها- بالأفكار

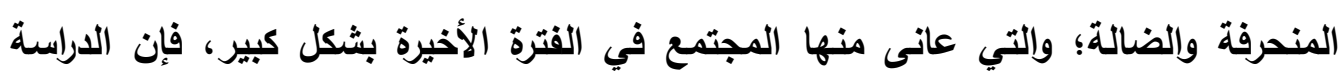

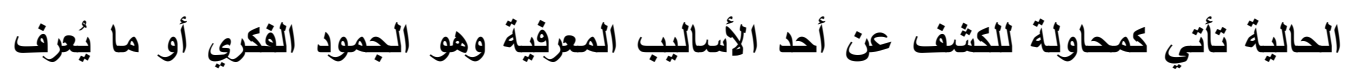

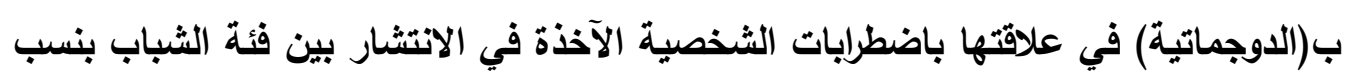
كبيرة وملحوظة، والتي منها (اضطراب الثخصية الحدية). 


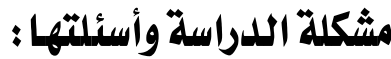

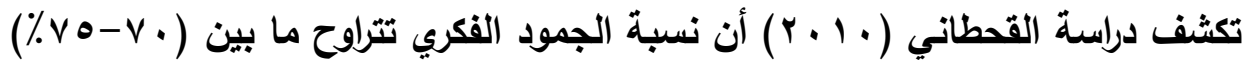

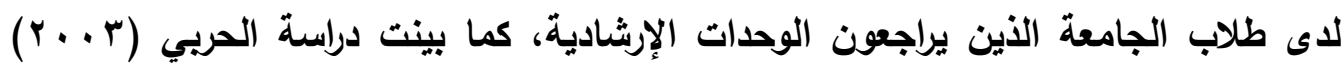

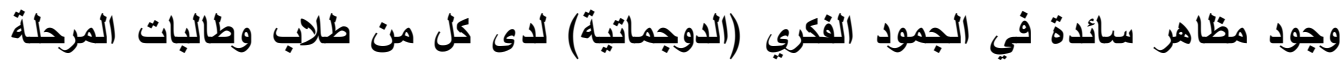

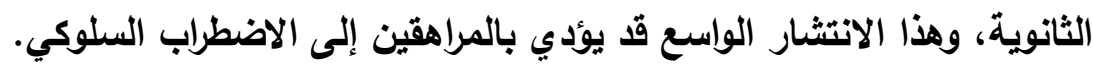

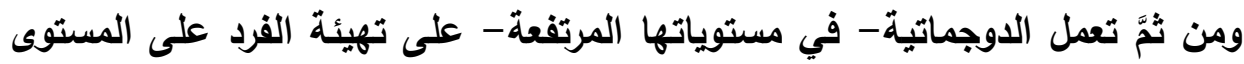

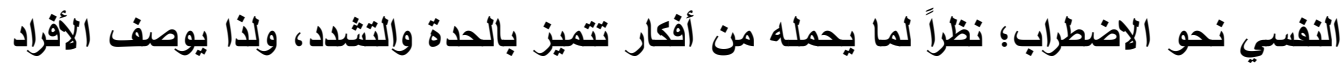
الدوجماتيون بأنهر منغلقون فكرياً، ومعرضون للعديد من الاضطرابات الثخصية.

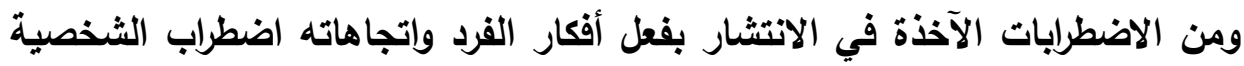

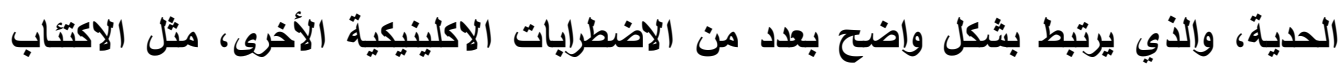
الذي يعتبر من أكثر الاضطرابات تلازما هذا الاضطراب، مما يجدر بالأخصائيين الانتباه لها لإنا عند تثخيص الاضطراب، حيث تحدد أحيانا نوع العلاج المقدم لهؤلاء المرضى (البشر،

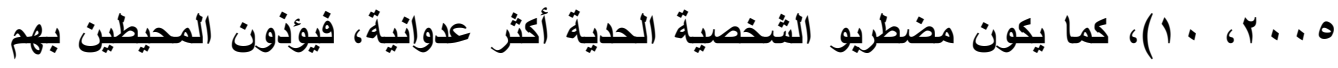
عبر تصرفاتهز العشوائية، وقد تصل المشكلات إلى الإيذاء البلني العنيف لارجة القتل .(Moore, Tull, \& Gratz, 2017, 27) ووفقاً لهذه الدلائل من جهة، وما يعايشه الباحث في الواقع التربوي من مشاهدات تؤكد ميل الطلاب في المراحل التعليمية المختلفة- والثانوية بصفة خاصة- إلى العنف،

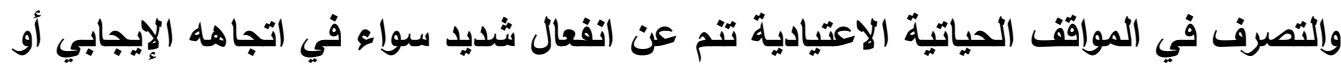

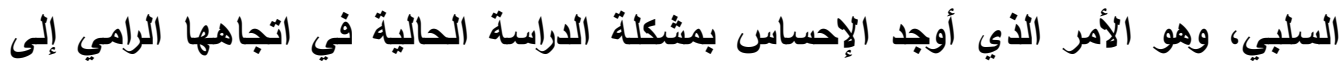

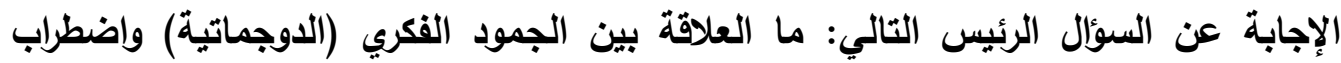

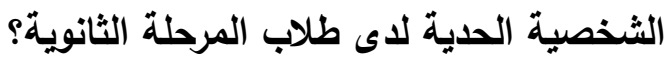
ويتضمن هذا السؤال مجموعة الأسئلة الفرعية التالية:

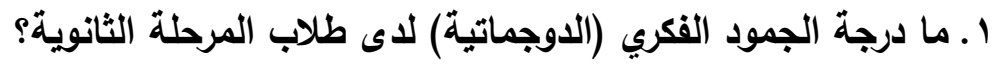
r. ما درجة اضطراب الثخصية الحدية لاى طلاب المرحلة الثانوية؟

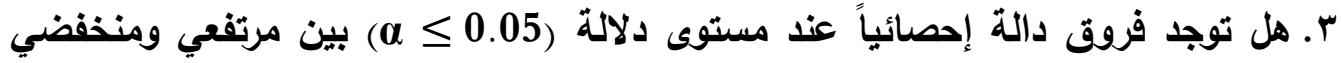
الدوجماتية في درجة اضطراب الثخصية الحدية لاى طلاب المرحلة الثانوية؟ دلاج 
ع ـ ما إمكانية التنبؤ باضطراب الشخصية الحدية من خلال الجمود الفكري (الدوجماتية) لاى طلاب المرحلة الثانوية؟ مابه

\section{أهداف الدراسلة:}

وفقاً لما تم طرحه من أسئلة، فإن الدراسة الحالية استهرفت العمل على الكشف عن طبيعة العلاقة بين الجمود الفكري (الدوجماتية) واضطراب الشخصية الحدية لدى طلاب المرحلة الثانوية بمحافظة قلوة، وتحديد درجة كل من الجمود الفكري (الدوجماتية) واضطراب الشخصية الحدية لايهم، وكذلك الكشف عن دلالة الفروق الإحصائية بين مرتفعي ومنخفضي

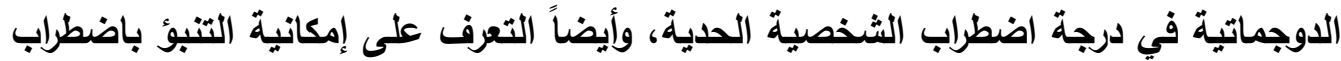
الثخصية الحدية من خلال درجة الدوجماتية لاى طلاب المرحلة الثانوية بمحافظة قلوة..

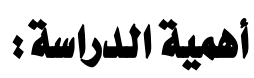
أولاً: الأهمية النظرية.

للاراسة الحالية أهمية نظرية، تتحدد في تناولها للأسلوب المعرفي (الدوجماتية) في علاقته باضطراب الثخصية، فعلى الرغم مما يمثله هذا الاضطراب من خطورة لدى الطلاب خاصة في مرحلة الثباب، إلا أن معظم الدراسات التي تناولته كانت على عينات سريرية، ومن ثم فهناك حاجة إلى دراسته لدى الحالات العادية من المتعلمين، وهو الأمر المتحقق في الاراسة الحالية عبر تناول هذين المتغيرين لاى عينة غير سريرية (عاديين). ثانياً: الأهمية التطبيقية. تكتسب الاراسة أهميتها التطبيقة من خلال سعيها نحو تحديد درجة انتشار متفيراتها لاى طلاب المرحلة الثانوية، ومن ثُّ تحديد التذخل الإرشادي المناسب لهذه الدرجة، كذلك تعمل الدراسة الحالية- من خلال ما سوف تكشفه من نتائج- إلى توجيه جهود القائمين على العملية التعليمية نحو وقاية طلاب المرحلة الثانوية من الأفكار غير السوية التي قد تقودهم إلى الاضطراب السلوكي أو التطرف الفكري.

حلدود الدراسة 1. الحد الموضوعي: اقتصرت الدراسة الحالية على تناول متغيري الجمود الفكري واضطراب الشخصية الحدية. 
r. r. الحد البشري: تحددت عينة الدراسة في طلاب المرحلة الثانوية بصفوفها الثلاث.

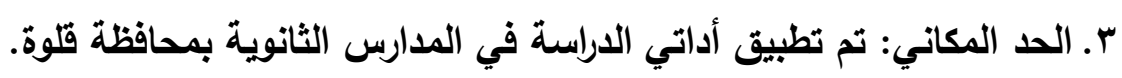

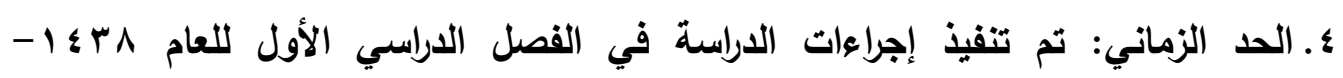
. 1 \& $q$

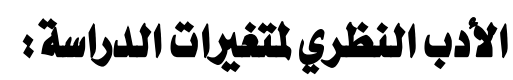

تناولت الداسة الحالية متغيري الجمود الفكري (الدوجماتية) واضطراب الثخاتهية

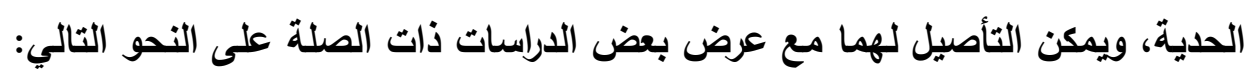
أولاً: الجمود الفكري (الدوجماتية).

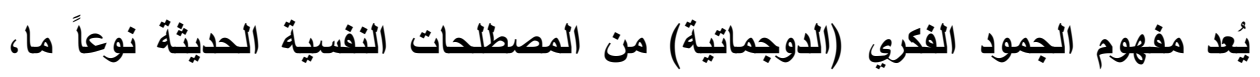

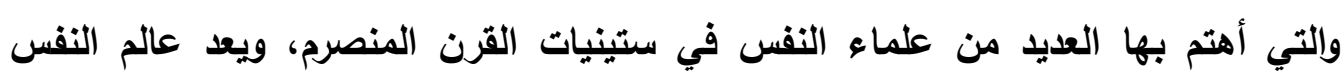

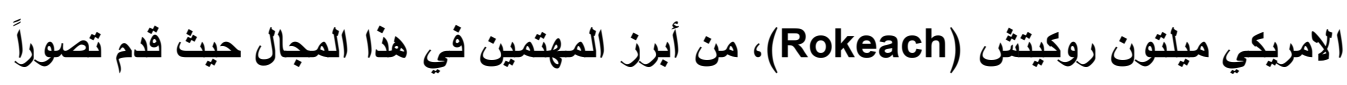

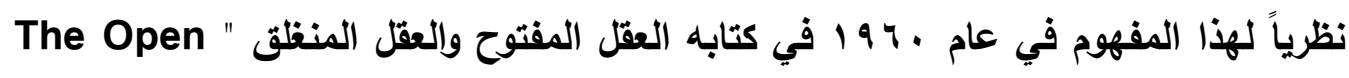
And Closed Mind

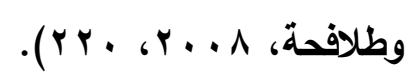
ويرى روكيتش Rokeach أن الدوجماتية سمة عامة من سمات الثخصية لها علاقة بالقدرة على تثكيل أنظمة معرفية جديدة، وقد قدم روكيتش مصطلح الدوجماتية على أنى أنه

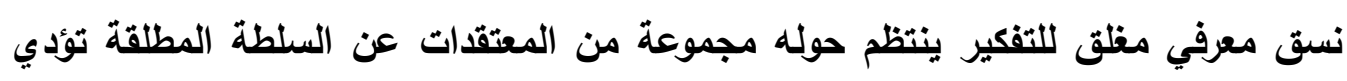

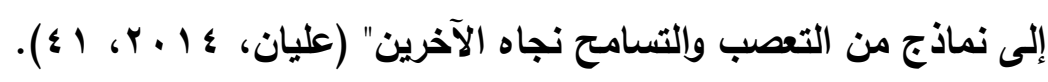

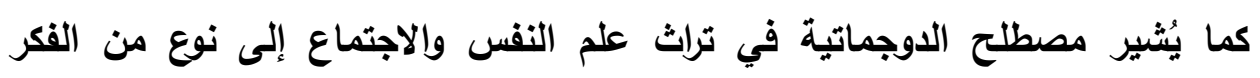

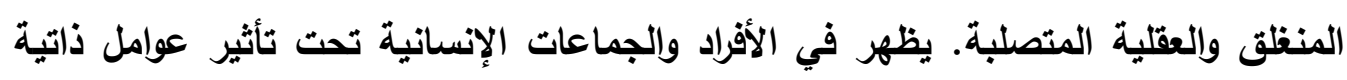

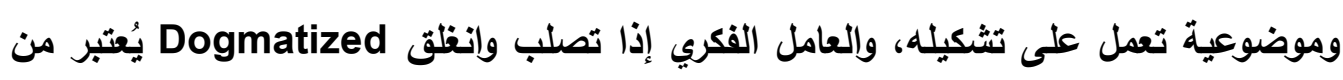

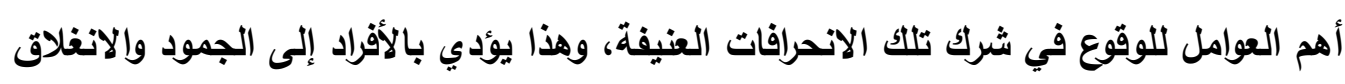

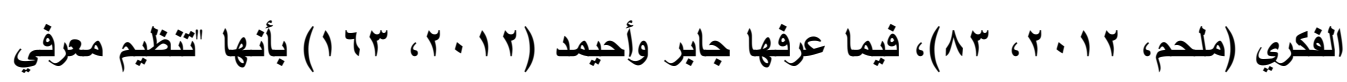

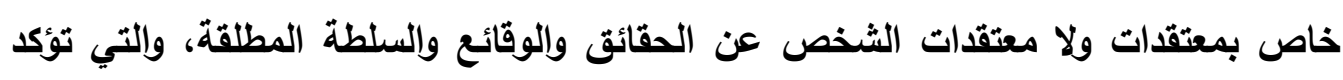

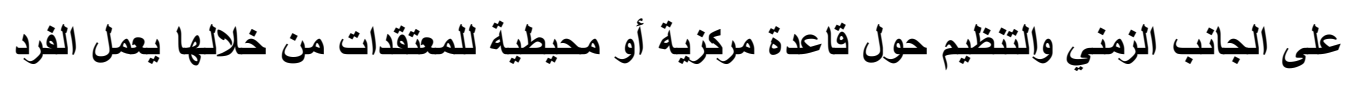
نماذج غير متسامحة في مقابل نماذج متسامحة مع الأخرين". 
كنلك قدمت العديد من النظريات النفسية تصوراً لتفسير الجمود الفكري، ومكوناته، وتئه

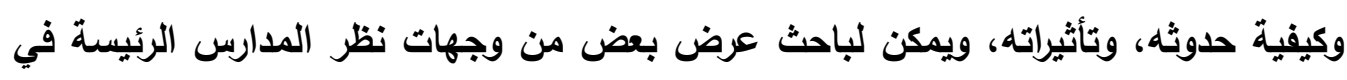

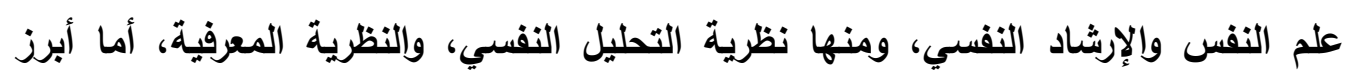

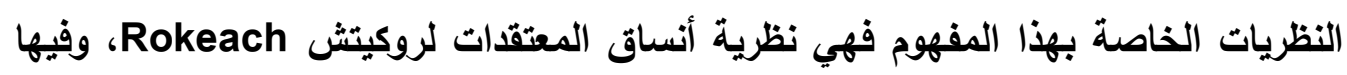

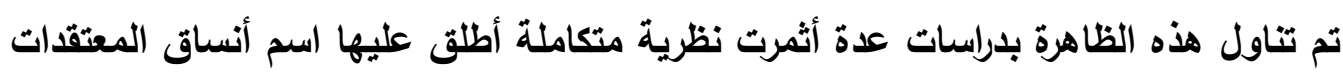

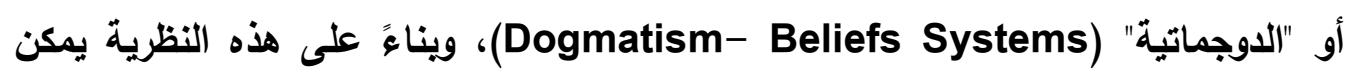

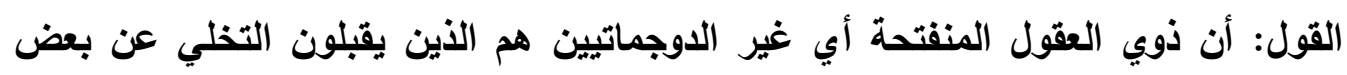

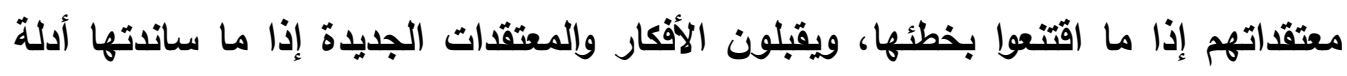

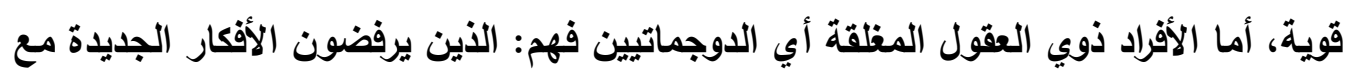

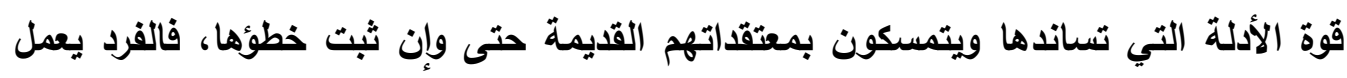

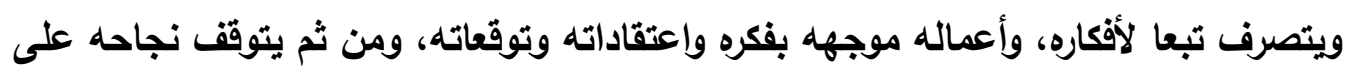

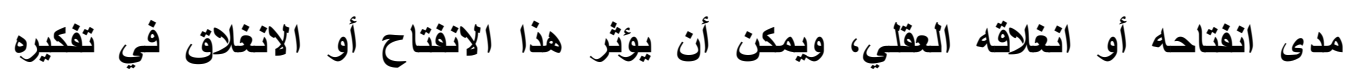

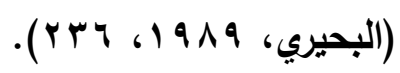

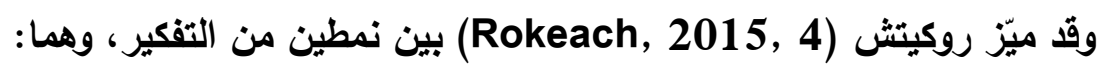

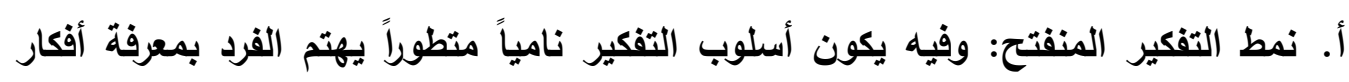

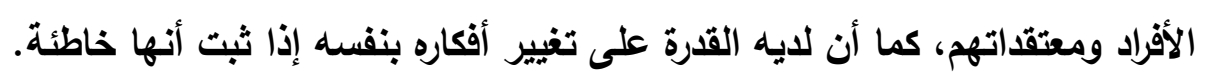

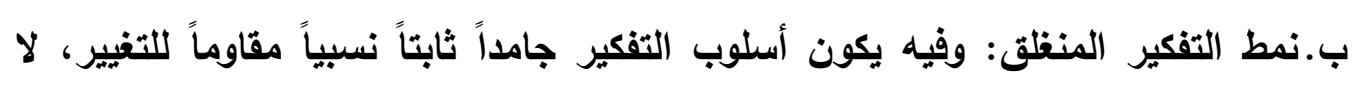

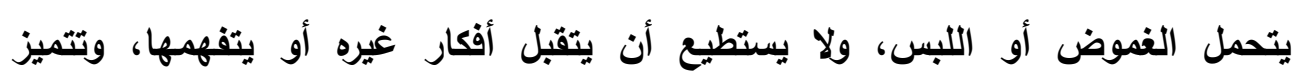

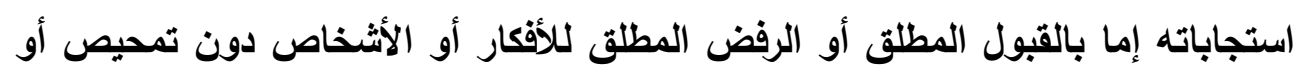
فحص.

(Gurney, وفقاًً لما أورده كل من: جورني وماكيون وتثريشيارد وهوليت McKeown, Churchyard\& Howlett, 2013, 937) ثلاثة أبعاد وهي: بعد المعتقات/ اللامعتقات، والبعد المركزي- المحيطي، وبعد المنظور الزمني. وفي ضوء ما سبق، يخلص الباحث إلى أن الثخص الاوجماتي يتسم بالتسرع

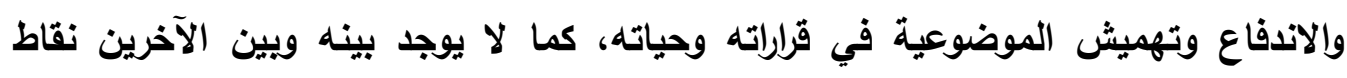


التقاء أو حوار، وذلك لتعصبه ضد الثقافات الأخرى كما أنه ذو نظرة تسلطية للحياة مع إيمان بالقوة كأسلوب رد دفاعي جيد للتغير، وهو ما يجعل من الأهمية بمكان دراسة هذه الندان النوعية

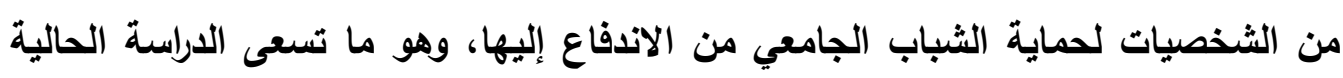

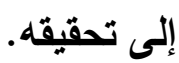

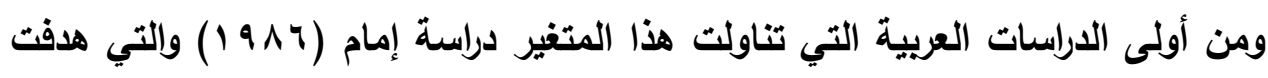

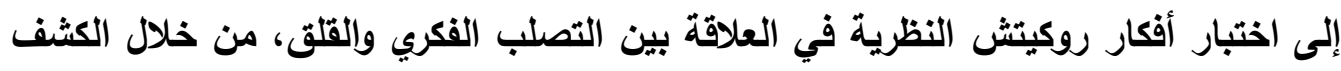

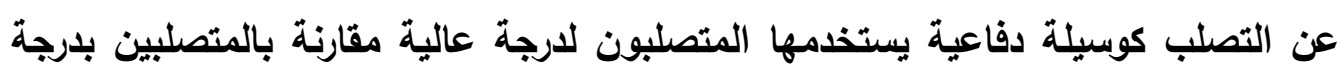

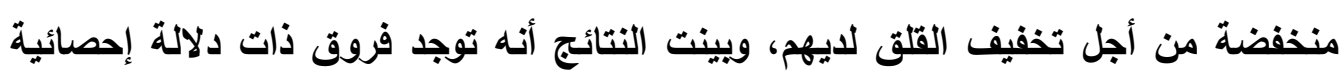

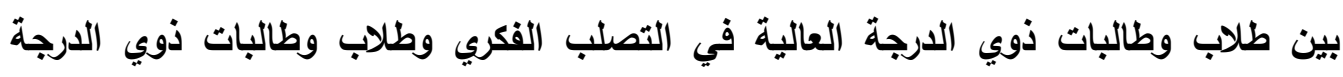

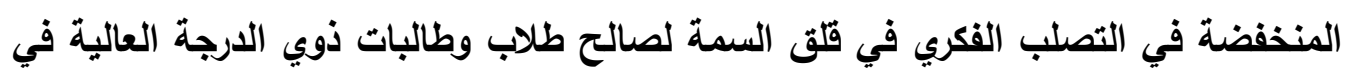

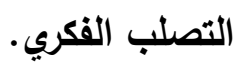

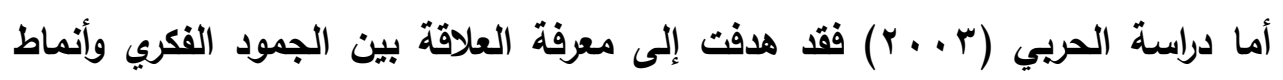

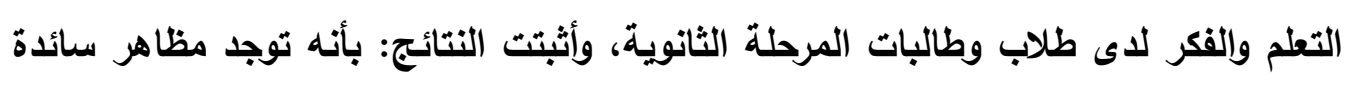

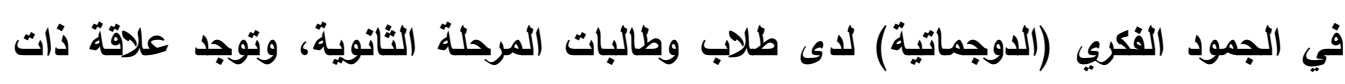

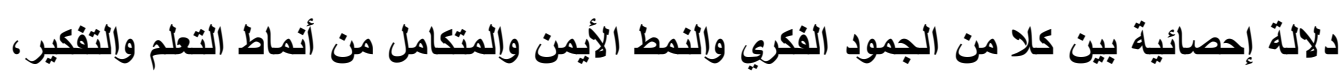
أما بالنسبة للنمط الأيسر فلا توجد علاثة دالة دالة إحصائياً.

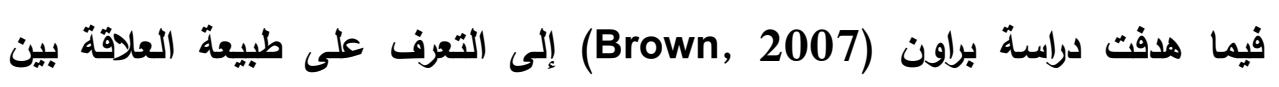

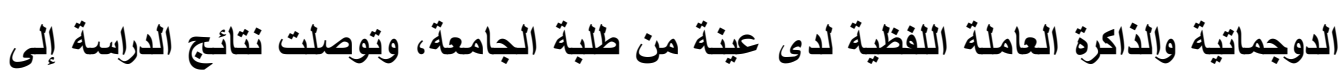

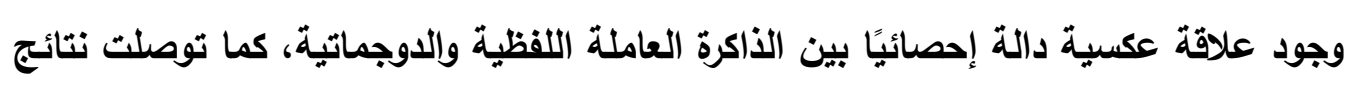

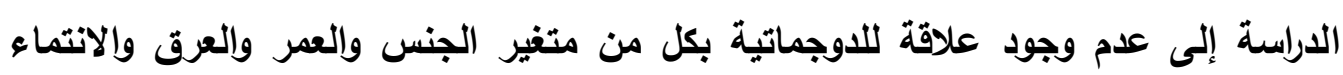

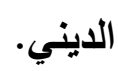

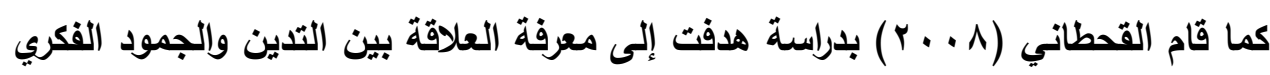

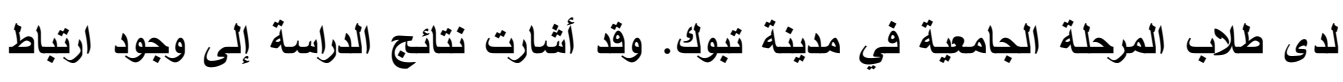

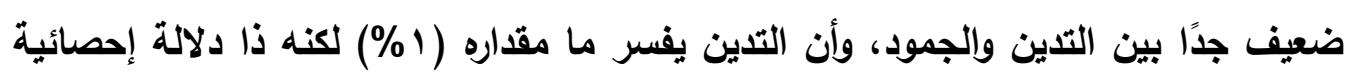
عند مستوى اللالة (ه ه . . ) تقريبا من الجمود الفكري لاى أفراد عينة الدارية. 


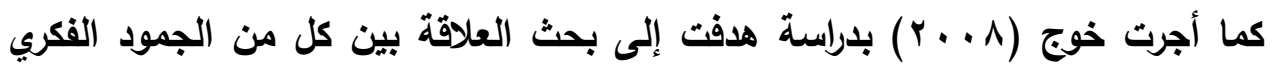

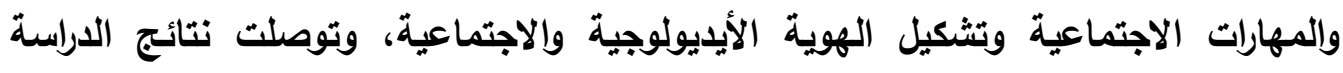
بصورة عامة إلى اختلاف مستوى الجمود الفكري ويعض أبعاد المهارات الاجتماعية وتثكيل الهوية باختلاف التخصص.

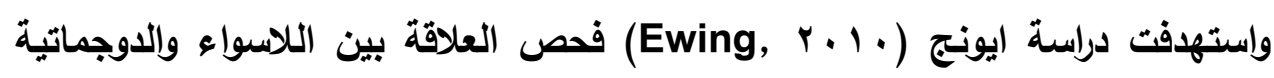
واختيار المتغيرات وإلعوامل الثخصية والاجتماعية لدي الطلبة المراهقين، وأثشارت الدراسة إلى الي الئ

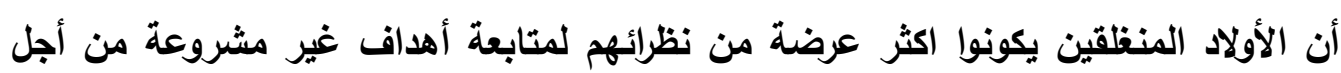

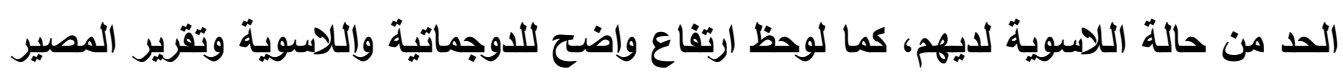

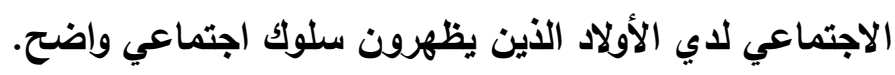

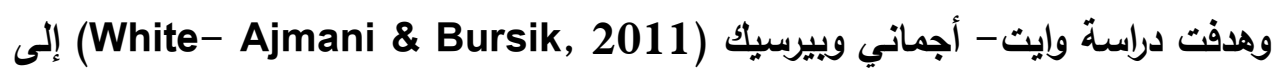

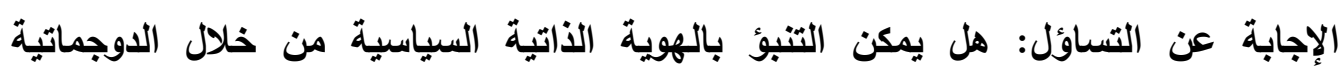

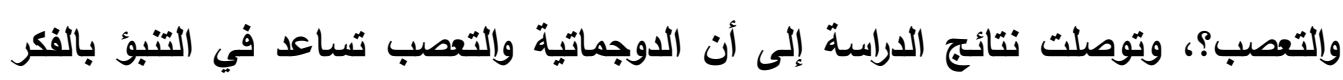
السياسي. فيما هدفت دراسة الثلاس (عابـr) إلى الكثف عن العلاقة بين أساليب المعاملة

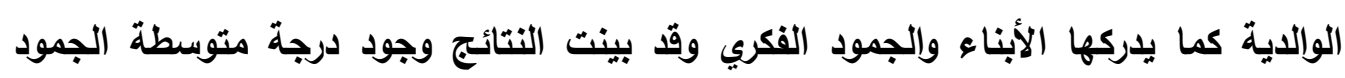

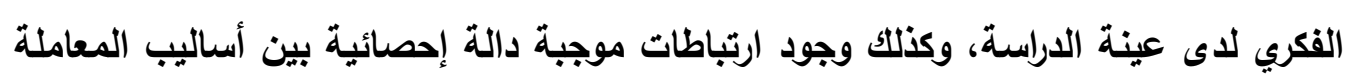

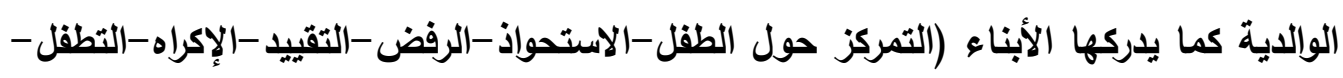

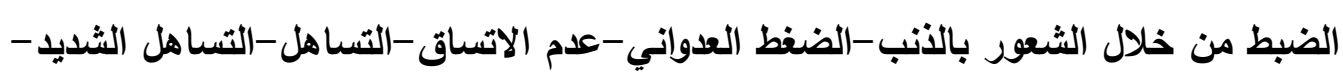

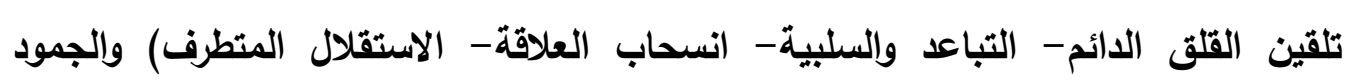
الفكري.

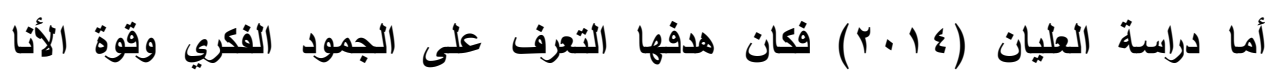

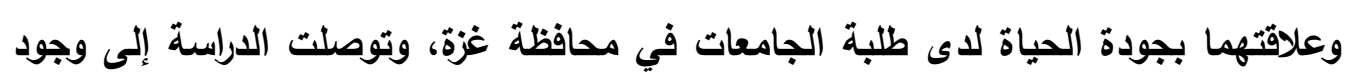

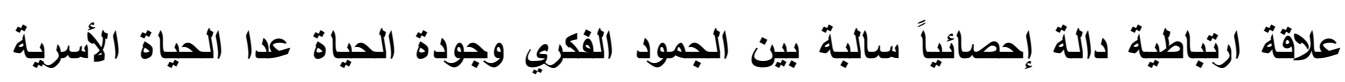

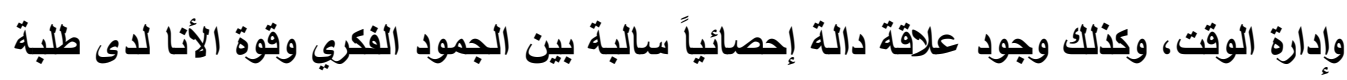

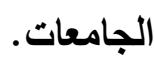


وهدفت دراسة سامية ومنصور (Samaie \& Mansour, 2015) إلى التعرف على

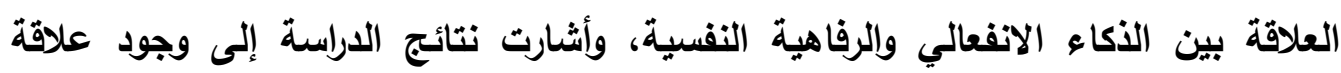

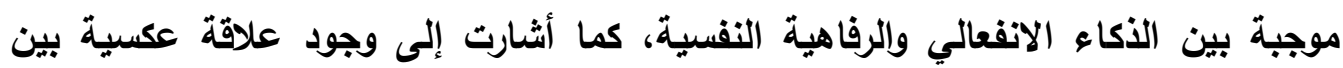

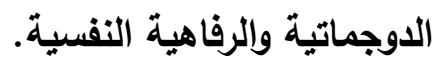

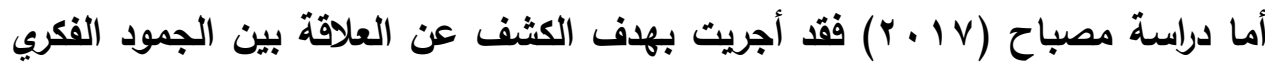

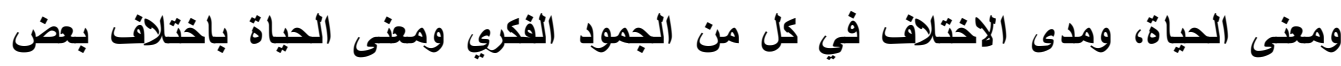

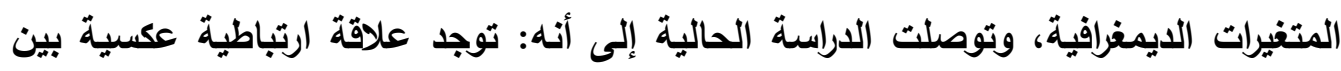

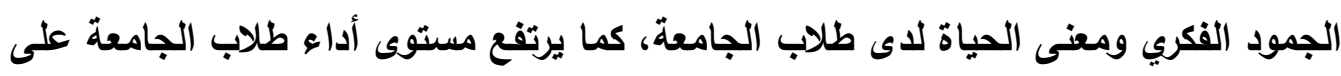
مقياس معنى الحياة للى منذفضي الجمود الفكري عنه لاى مرتفعي الجمود الفكري. ثانياً: اضطراب الثخصية الحدية. يُقصد باضطراب الثخصية الحدية وفق الاليل التثخيصي الاحصائي الرابع والذامس

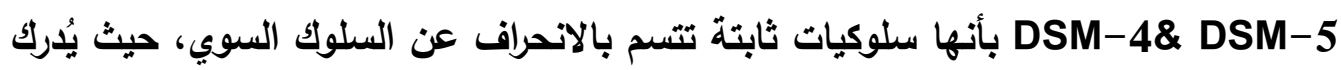

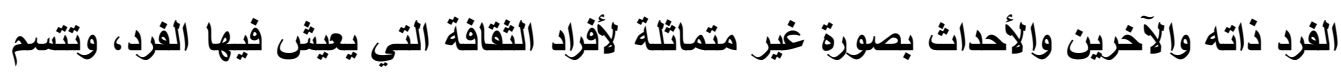

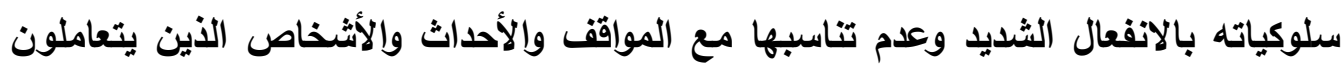

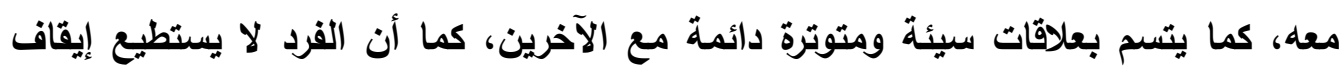

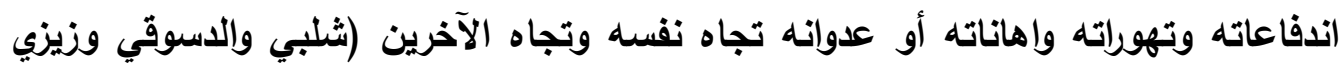

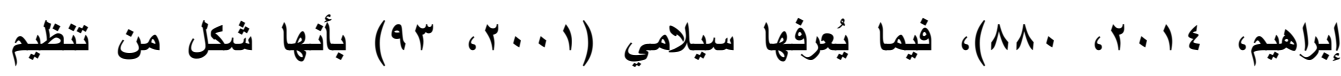

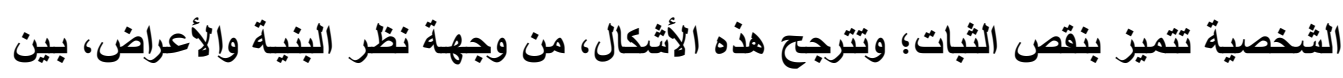

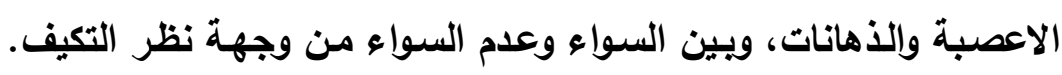

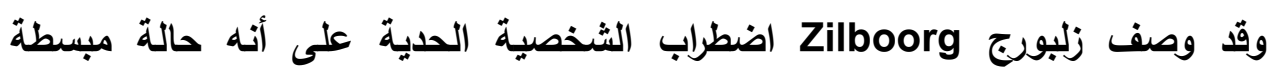

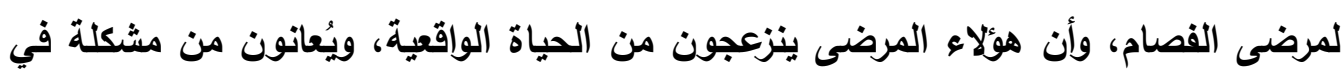

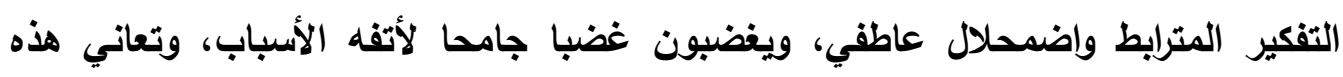

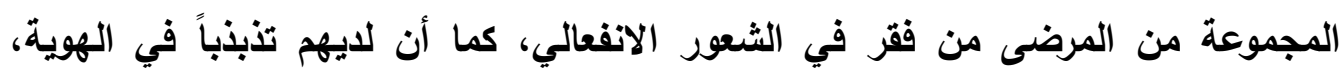

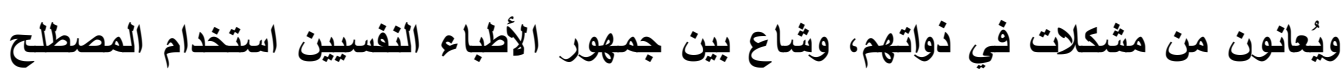

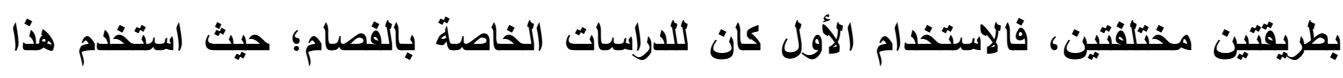

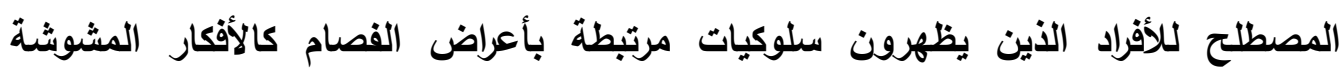


والتفككية أما الاستخدام الثاني فكان يُشير إلى الأفراد الذين يُعانون من تقلب انفعالي (Finley, Buffett- Jerrott, Stewart\& Millington, 2002, 88) والصفة الغالبة والمميزة لاضطراب الثخصية الحدية هي التطرف في معظم أمور

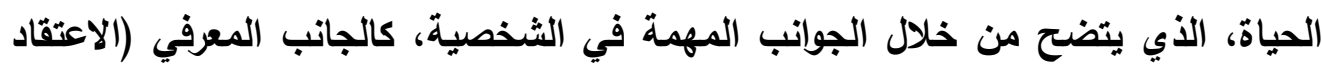

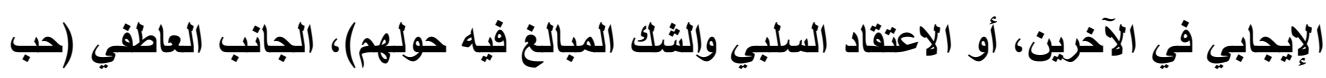

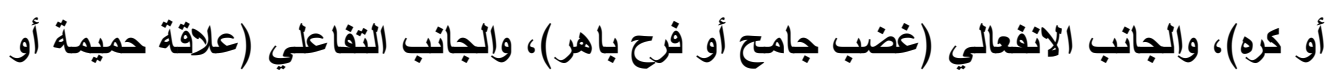

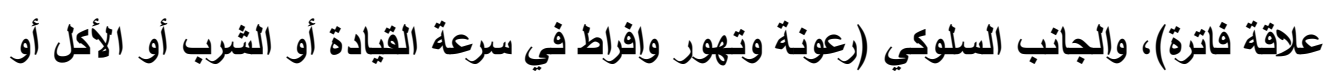

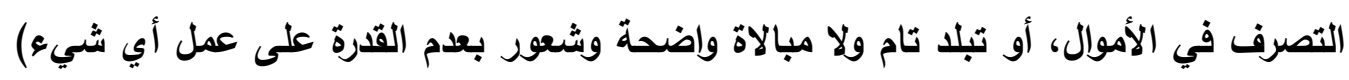

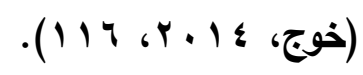

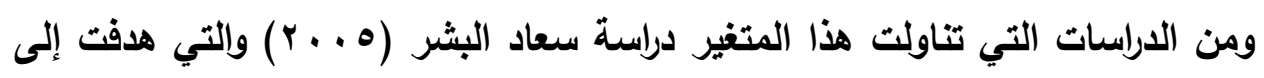

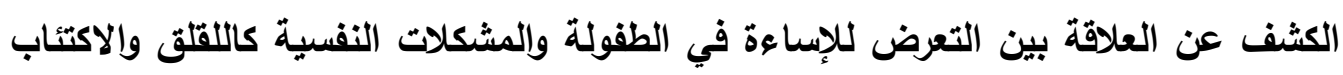

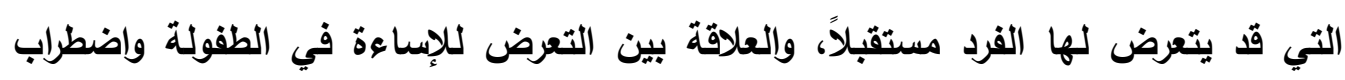

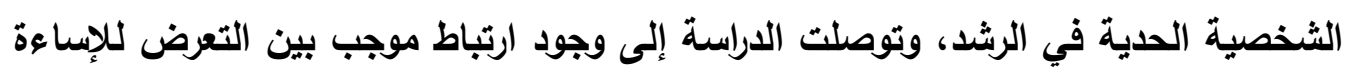

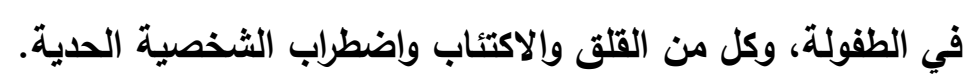

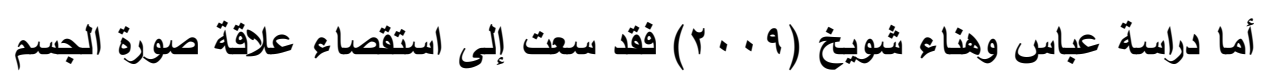
والثخصية البينية (الحدية) ببعض الاضطرابات السيكوسوماتية لاى طلاب الجامعة، وأظهرت

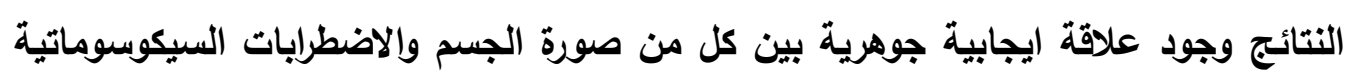

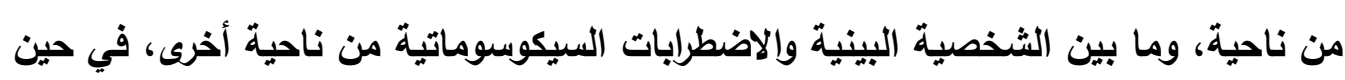
لم توجد علاقة بين صورة الجسم والثخصية البينية.

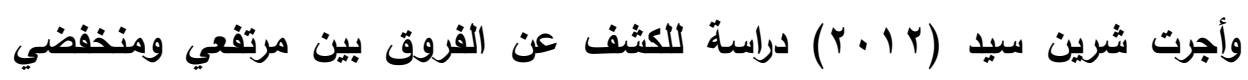

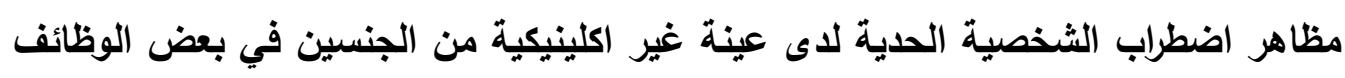

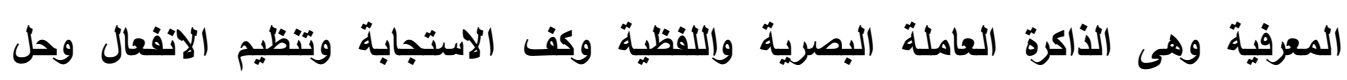

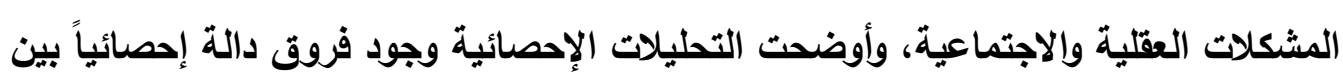

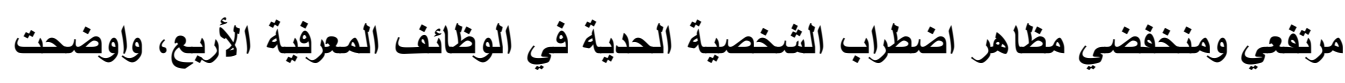

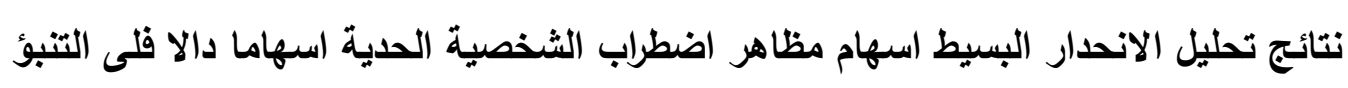

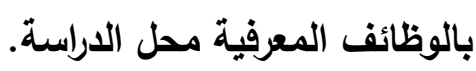


فيما هدفت دراسة أبو زيد (r. PV) إلى التعرف على فاعلية التدريب على اليقظة

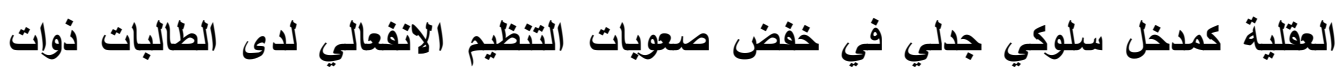

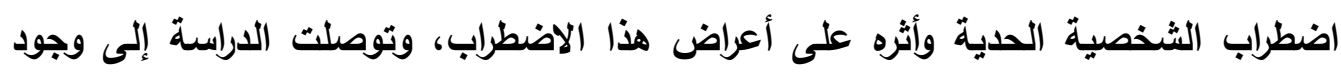

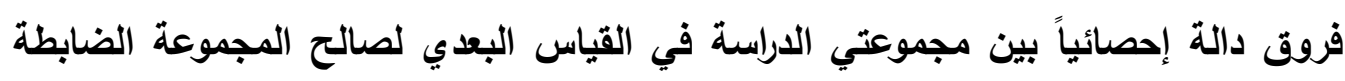

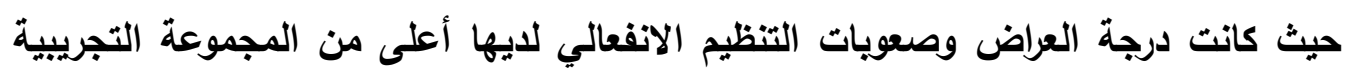

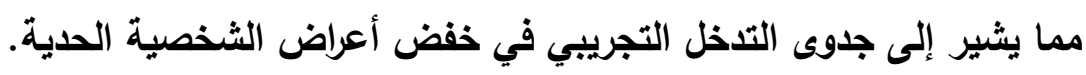

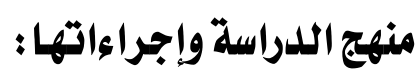
اعتمدت الاراسة الحالية على استخدام المنهج الوصفي في صورته الارتباطية، حيث الهاء

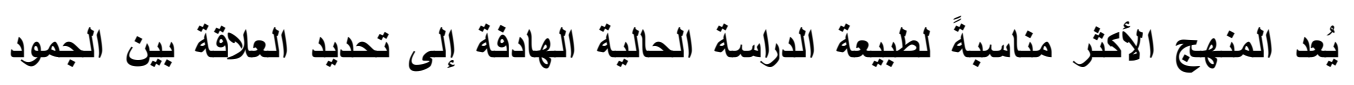
الفكري (الدوجماتية) وبين اضطراب الثخصية الحدية لاى طلاب المرحلة الثانوية بمحافظة قلوة.

\section{- مجتمع وعينة الدراسة: - مون.}

تكون مجتمع الدراسة من جميع الطلاب الذكور بالمرحلة الثانوية؛ والبالغ عدادهم

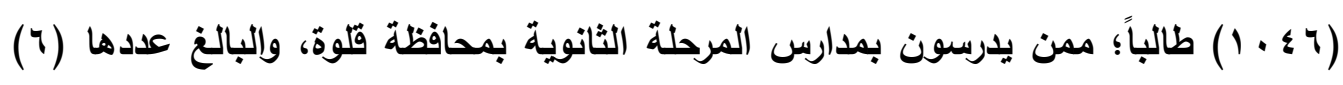

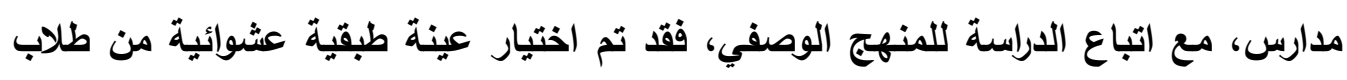

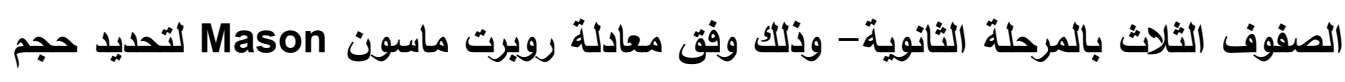

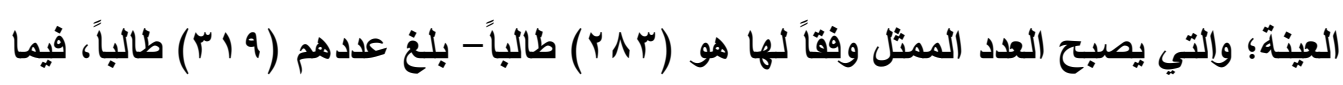

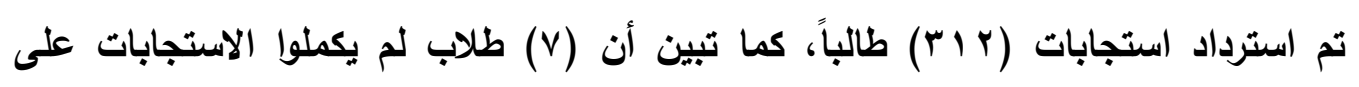

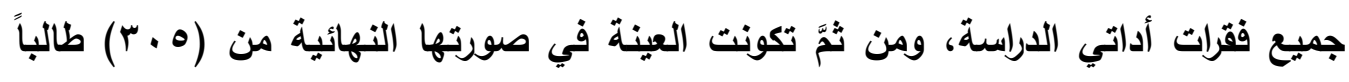

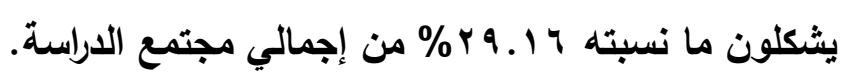

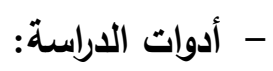

اعتمدت الاراسة الحالية على استخدام أداتين وهما:

أولاً: مقياس روكيتش للدوجماتية الصورة (E ) . :

أعد هذا المقياس ملتون روكيتش Rokeach في العام (1907) وسعى في تطويره

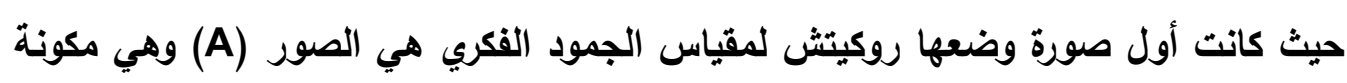

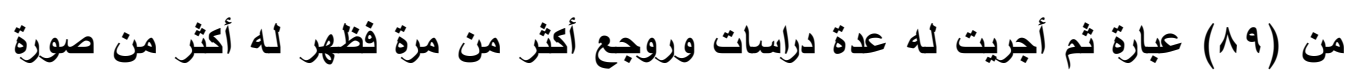


وهي على التوالي (B, C, D, E) وتحتوي الصورة (D) على (T) عبارة في حين تحتوي

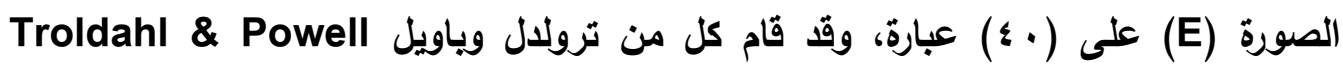

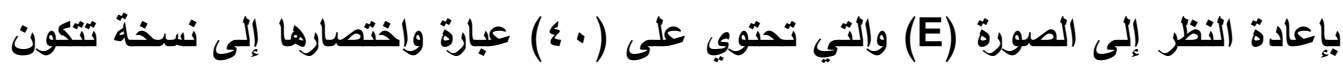

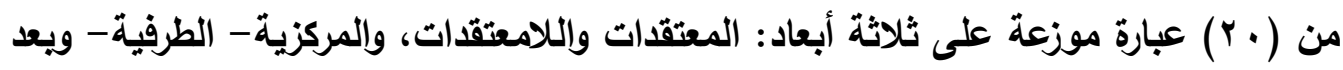

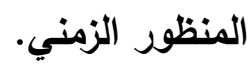

وللتحقق من صدق وثبات المقياس في الدراسة الحالية، قام الباحث بتطبيقه على عينة

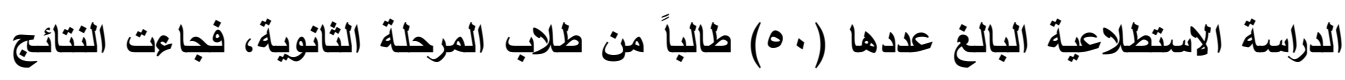
كما يلي: (1) الصدق: قام الباحث بحساب صدق المقياس باستخدام طريقة الاتساق الداخلي؛ والتي

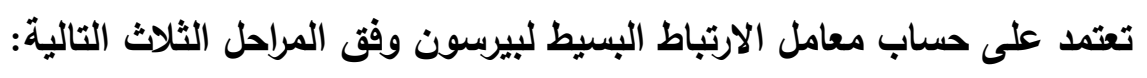

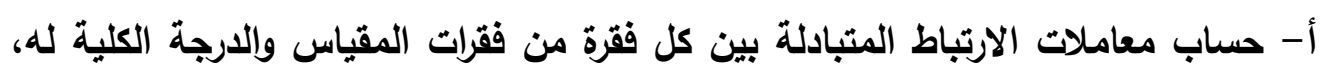

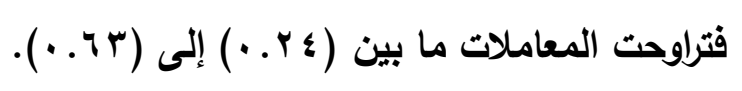

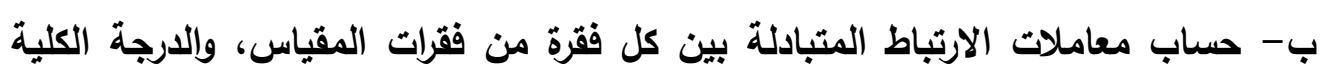

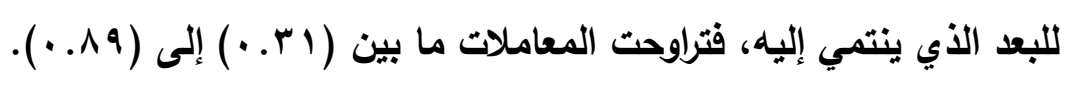

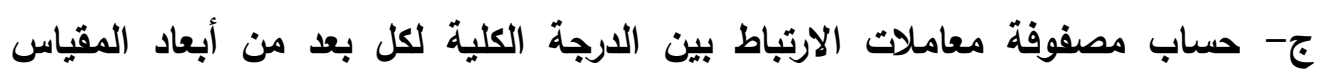

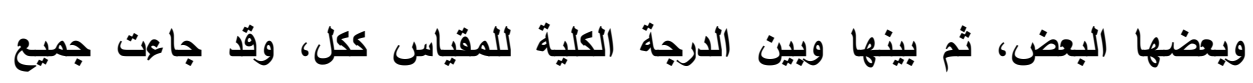

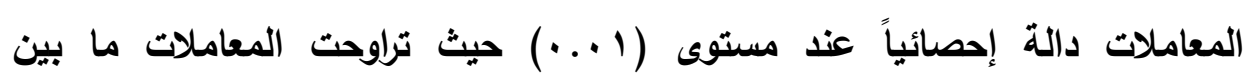

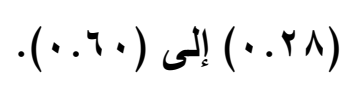

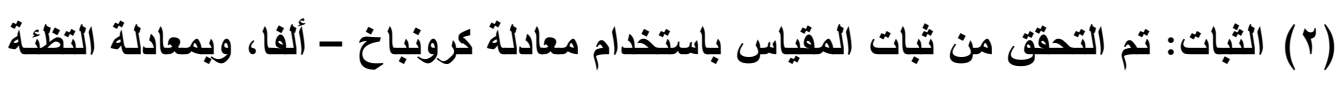

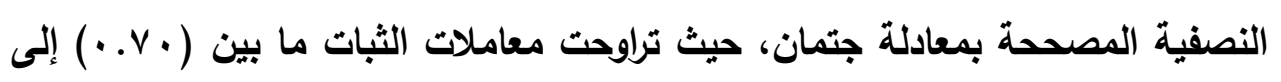
ع (Av)

$$
\text { عبر الاراسة الحالية. }
$$

ثانياً : قائمة أعراض الشخصية الحدية النسخة المختصرة.

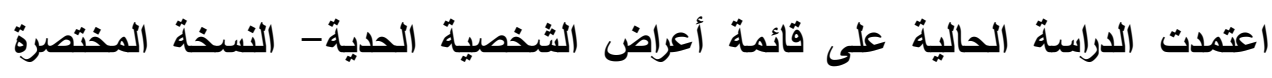
Short Version Borderline Symptom List (BSL- 23) (Bohus, Kleindienst, Limberger, Stieglitz, Domsalla\& Wolf, وزملاؤه 
(2009 لقياس أعراض الثخصية الحدية تحت مسمى (قائمة الأعراض الحدية- النسخة

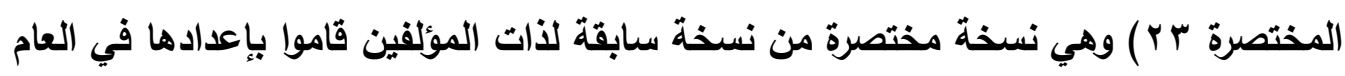

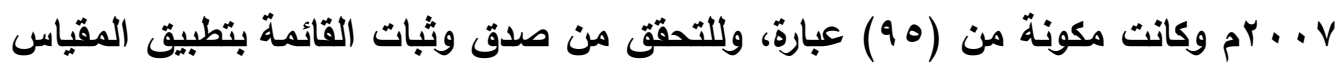

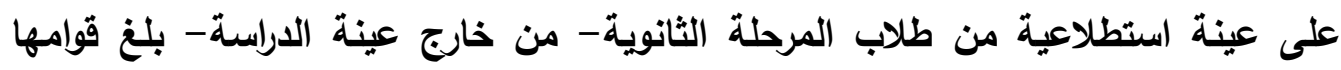
(•) طالباً؛ وذلك بغرض حساب صدق وثبات المقياس في الاراسة الحالية، وذلك على النحو

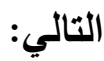

(1) الصدق: تم حساب الصدق البنائي للقائمة، عبر حساب معاملات الارتباط حساب معاملات الارتباط المتبادلة بين كل فقرة من فقرات المقياس والدرجة الكلية له،

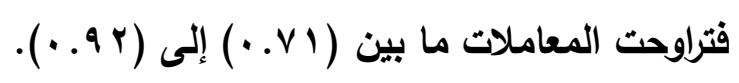

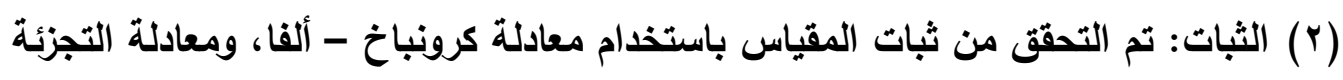

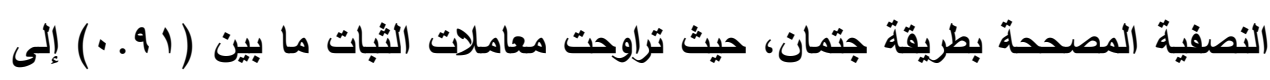

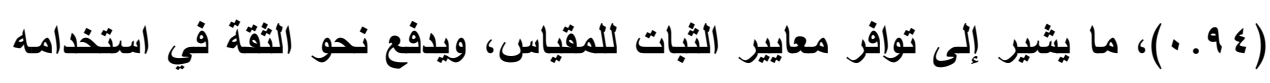
عبر الداسة الحالية. تتائج اللدراسة ومناقشتها وتفسيرها : نتيجة السؤال الرئيس ومناقثتها وتفسيرها: والذي نصه: "ما العلاقة بين الجمود الفكري (الدوجماتية) واضطراب الثخصية العدية الثية

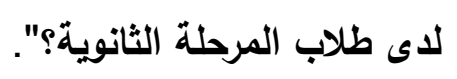
حيث تمت الإجابة عن هذا السؤال من خلال حساب مصفوفة معاملات الارتباط المتبادلة بين الدرجة الكلية للجمود الفكري وأبعاده الفرعية والدرجة الكلية لكابة للاضطراب

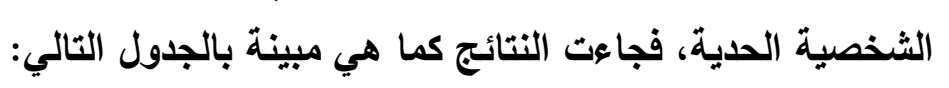

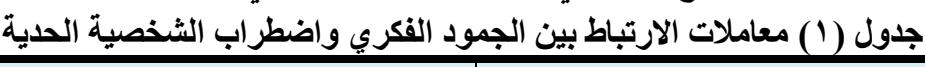

\begin{tabular}{|c|c|c|}
\hline \multicolumn{2}{|c|}{ الارجة الكلية لاضطراب الثخصية الحدية } & \multirow[b]{2}{*}{ أبعاد الجمود الفكري } \\
\hline مستوى الدلالة & قايمة (ر) & \\
\hline$\because$ & 0 & المتنقدات واللامعتقدات \\
\hline$\therefore$ & $\therefore 9$ & المركزية ـ الطرفية \\
\hline$\because 0$ & 0 & المنظور الزمني \\
\hline$\therefore 1$ & . & الدرجة الكلية للمقياس \\
\hline
\end{tabular}




$$
\text { يتبين من الجدول (1) التالي ما يلي: }
$$

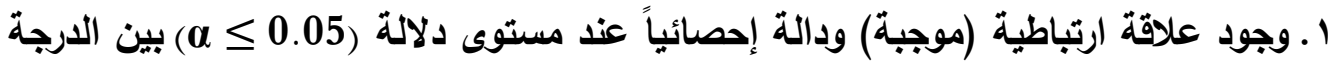

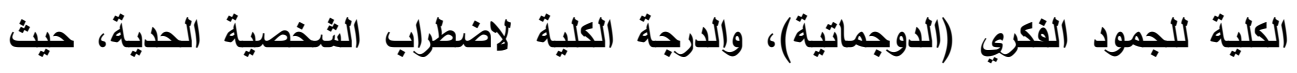
بلغت قيمة معامل الارتباط بينها (rr..)، وهي قيمة دالة إحصائياً عند مستوى

$$
\cdot(\cdot \cdot 1)
$$

r. وجود علاقة ارتباطية (موجبة) ودالة إحصائياً عند مستوى دلالة (a 0.05$)$ بين الأبعاد

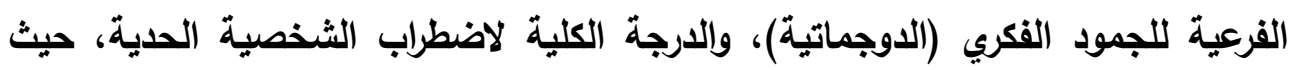
تراوحت قيم معاملات الارتباط البسيط لبيرسون ما بين ( اء ا. ·)، وهي قيمة دالة إحصائياً عند مستوى (q ب. - ).)

ومع عدم وجود دراسات استهدفت تناول العلاقة المباشرة بين الجمود الفكري (الدوجماتية) واضطراب الثخصية الحدية- في حدود علم الباحث - فإنه يمكن تلمس بعض النتائج التي تبلو قريبة الصلة من النتيجة الحالية، حيث تختلف النتيجة الحالية في دلالتها

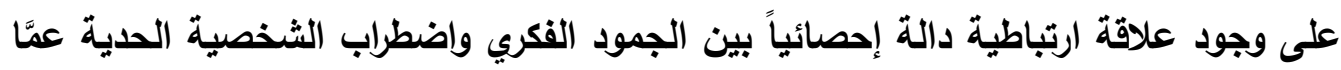
كثفت عنه نتيجة دراسة زينب التميمي (10 ا ب ) التي أظهرت عدم وجود علاقة ارتباطية بين الجمود الفكري والعصابية (كأحد العوامل الخمس الكبرى في الثخصية)، بينما تثفق مع نتيجة

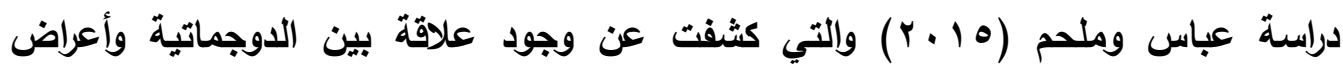
الاكتئاب.

كما تتفق النتيجة الحالية مع نتائج دراسة هبه حسن (10 ب) التي أشارت إلى وجود علاقة ارتباطية دالة إحصائياً بين معظم المخططات المعرفية اللاتوافقية ويين اضطراب الثخصية الحدية. ويعزو الباحث النتيجة الحالية في دلالتها على وجود علاقة ارتباطية دالة إحصائياً عند مستوى دلالة (a 0.05$)$ بين الجمود الفكري واضطراب الشخصية الحدية إلى كون الجمود الفكري يعبر في درجته المرتفعة عن انغلاق في الفكر؛ بحيث لا يرى الطالب سوى نفسه، وهو الأمر الأي ينعكس على شخصية الفرد؛ التي تتميز حينئ بالاندفاعية الشديدة لإعلاء قيمة ما يراه، وهو ما قد ينعكس على عدم استقرار علاقته بالآخرين نتيجة التصادمات المتكررة بينه ويينهم، وهو ما يفسر وجود علاقة بين الجمود الفكري واضطراب الشخصية الحدية. 
وما ذهب إليه الباحث تدعمه الأدبيات التربوية الخاصة بتفسير الجمود الفكري، حيث أليث

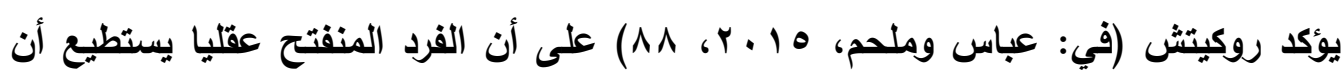

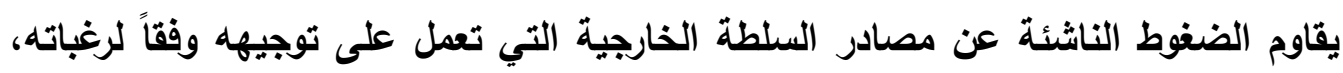
أما المنظلق عقلياً فإنه ينساق إلى رغبات وأهواء هذه المصادر ويعمل وفقاًا لها. نتيجة السؤال الأول ومناقثتنها وتفسيرها:

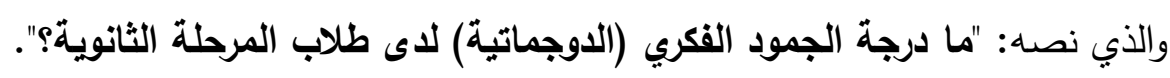

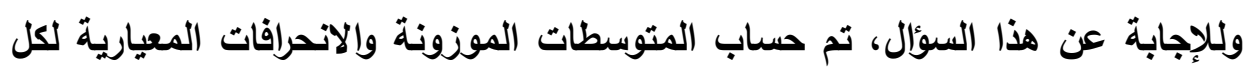

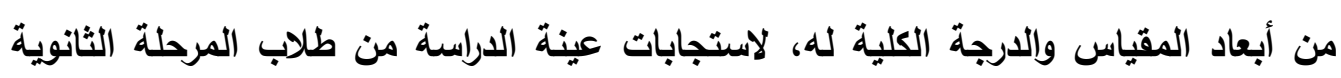

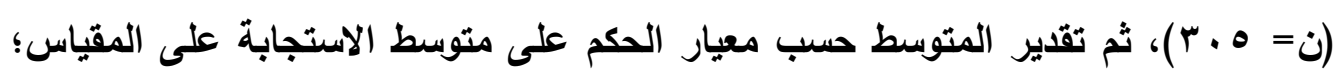

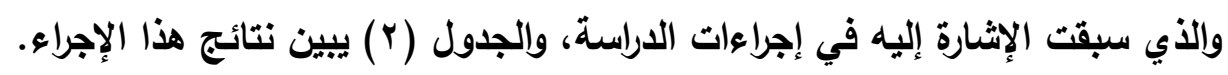

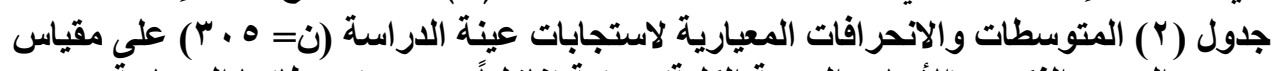

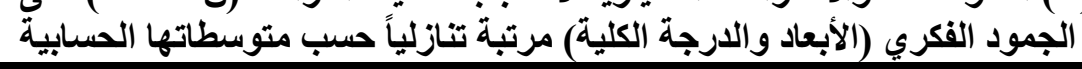

\begin{tabular}{|c|c|c|c|c|c|}
\hline الرتبة & درجة التوفر & 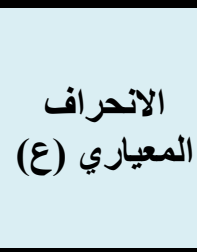 & $\begin{array}{c}\text { الموزون } \\
\text { (م) }\end{array}$ & البعد & البعد \\
\hline 1 & متوسطة & 1.05 & 3.84 & اللامعتققدات- & 1 \\
\hline$r$ & متوسطة & 1.11 & 3.81 & المنظور الزمني & $r$ \\
\hline$r$ & متوسطة & 1.12 & 3.78 & الطرفيةزية - & $r$ \\
\hline & متوسط & 1.09 & 3.81 & لادرجة الكلية & \\
\hline
\end{tabular}

يتبين من الجدول (r) أن متوسط استجابات عينة الاراسة من طلاب المرحلة الثانوية

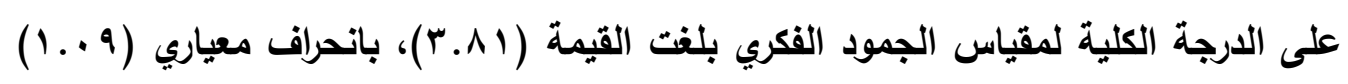

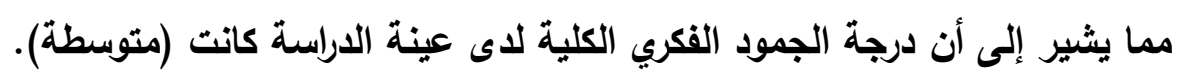

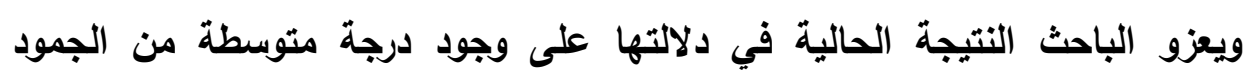

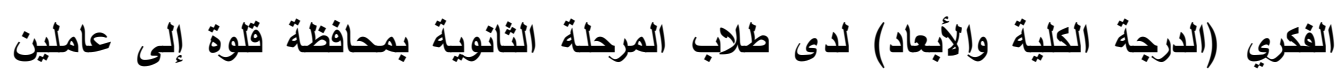

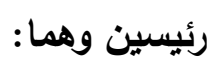


1- طبيعة المرحلة العمرية التي يمر بها طلاب المرحلة الثانوية، وهي مرحلة المراهقة

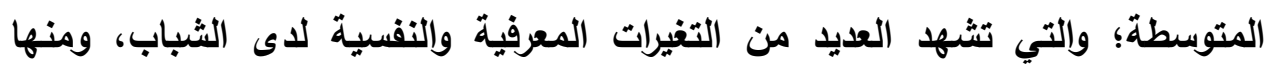

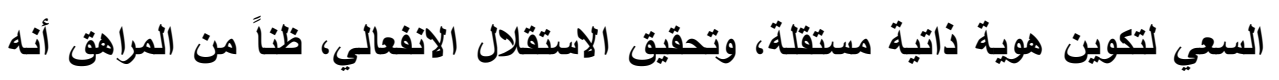

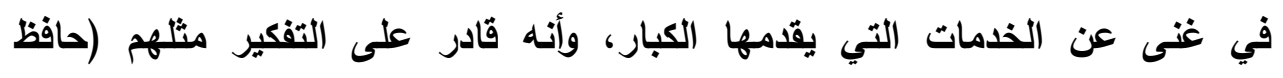

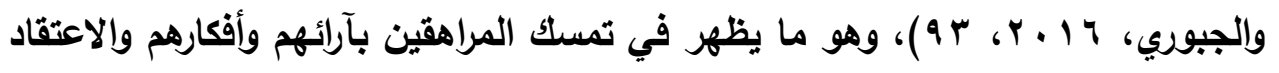

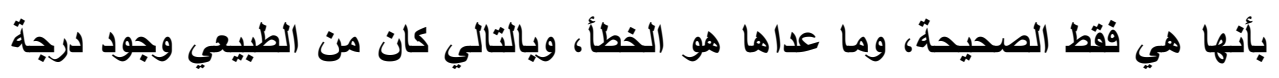
ما من الدوجماتية لدى الطلاب في المرحلة الثانوية.

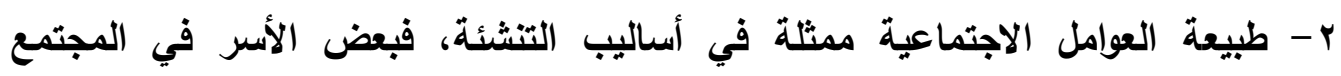

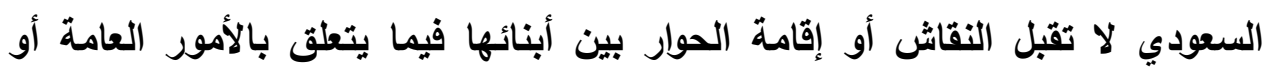

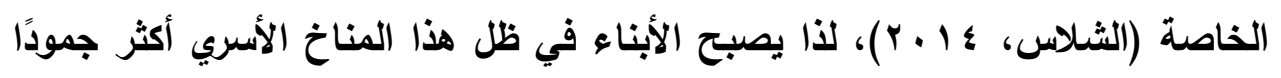

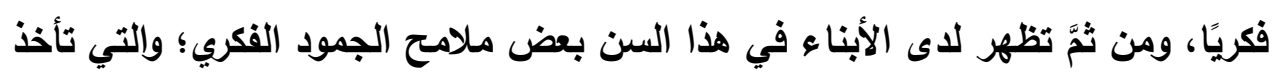

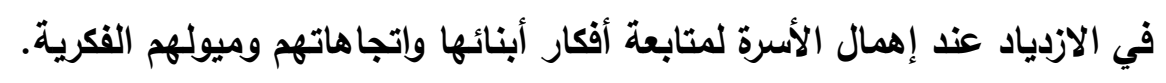

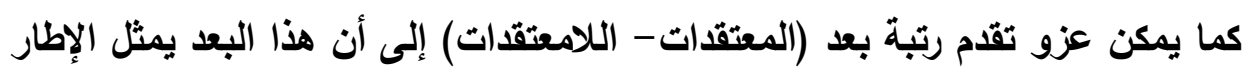

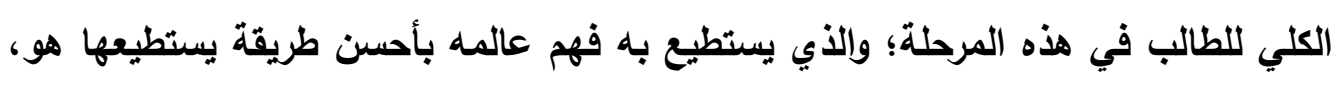

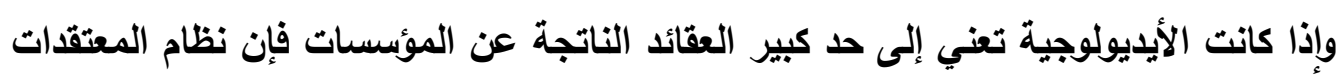

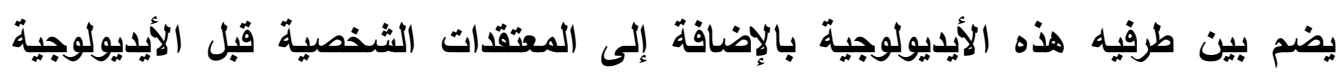
"Per-Ideological Beliefs" نتيجة السؤال الثاني ومناقشتها وتفسيرها :

والذي نصه: "ما درجة اضطراب الثخصية الحدية لاى طلاب المرحلة الثانوية؟".

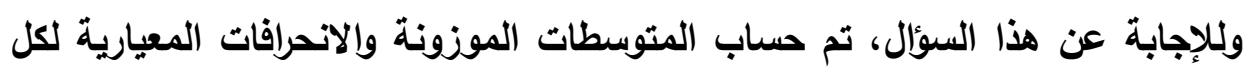

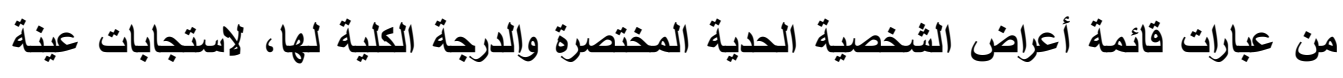

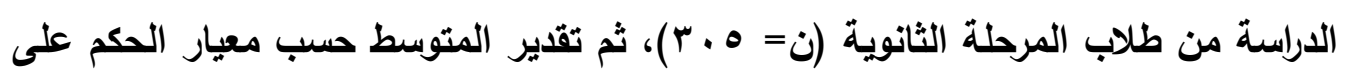

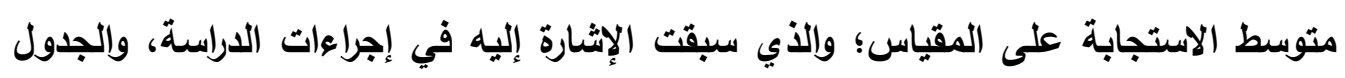

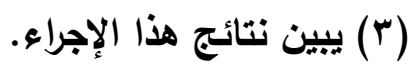


الجمود الفكري (الدوجماتية) وعلاقته باضطراب الشخصية الحدية لدى طلاب المرحلة الثانوية بمحافظة قلوة

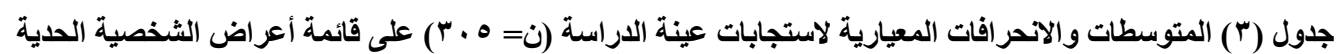

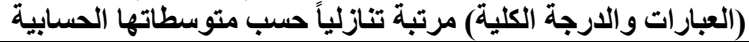

\begin{tabular}{|c|c|c|c|c|c|}
\hline 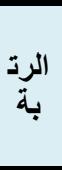 & التوفرة & الانحرا & الموزون & 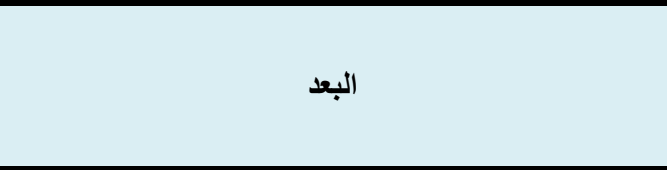 & رقم العبارة في \\
\hline 1 & متوسط & 1.45 & 2.75 & ل يَّ أتخيل بأنه سيتركني. & 1 \\
\hline r & ضعيفة & 1.38 & 2.43 & 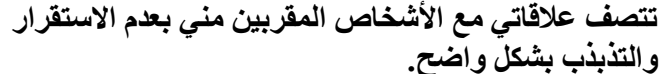 & r \\
\hline$r$ & ضعيفة & 1.36 & 2.43 & 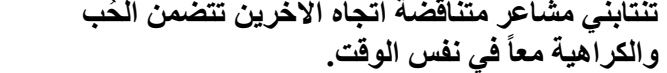 & 11 \\
\hline$\varepsilon$ & 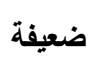 & 1.32 & 2.40 & ـ ك والريبة اتجاه نوايا الآخرين عندما & 9 \\
\hline$\bullet$ & ضعيفة & 1.37 & 2.38 & تناول الطعام متهور واندفاعي حتى في قيادة السيارات أو في & $1 \pi$ \\
\hline 7 & ضعيفة & 1.35 & 2.36 & ألاحق الشخص العز & 1. \\
\hline$v$ & ضعيفة & 1.08 & 2.34 & الاعرف سبب ذلكت. المقين مني يظهرون عدم محبتهم لي دون ان & $r$. \\
\hline$\wedge$ & ضعيفة & 0.96 & 2.26 & تسبب مزاجيتي انزعاج الا & $1 \varepsilon$ \\
\hline 9 & ضعيفة & 1.11 & 2.25 & 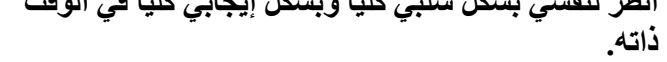 & r \\
\hline $1 \cdot$ & ضعيفة & 1.36 & 2.24 & أشقرقة. وكأنني أظهر للأخرين بشكل مختلف عما أنا عليه في & ir \\
\hline $1 \cdot$ & ضعيفة & 1.42 & 2.24 & 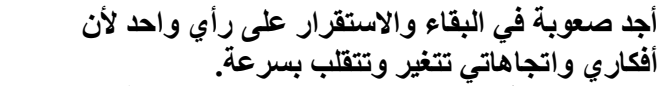 & $r$ \\
\hline ir & ضعيفة & 1.42 & 2.23 & اندفع للقيام بأعمآل متهورة تكون عو اقبها وخيم & $\varepsilon$ \\
\hline ir & ضعيفة & 0.98 & 2.21 & & 11 \\
\hline $1 \varepsilon$ & ضعيفة & 1.01 & 2.20 & الكمية التي اتلجأ للكول أو أقوم بتعاطي العقاقير فإنني أبالغ في & rr \\
\hline 10 & ضعيفة & 0.97 & 2.19 & مرات فُمات مضى بايذاء جسدي أو جرح جلدي بنفسي بضع & 10 \\
\hline 17 & ضعيفة & 0.95 & 2.17 & ترافقتي مشاعر داخلية بعدم الراحة دون سبب واضح. & 17 \\
\hline iv & ضعيفة & 0.99 & 2.16 & عدوانياً اضرب الآخرين أو أحطم الأشيّاء. لارجه السي اصبح & iv \\
\hline 11 & 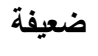 & 1.36 & 2.14 & لقد سبق لي وأن فكرت في إنهاء حياتي بشكل جدي. & 7 \\
\hline 19 & ضعيفة & 1.28 & 2.11 & 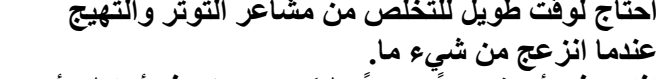 & $r \mu$ \\
\hline$r \cdot$ & ضعيفة & 0.96 & 2.10 & 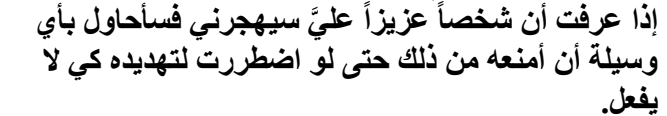 & 19 \\
\hline rl & ضعيفة & 1.33 & 2.09 & مزاجي متقلب بدون وجود أي سبب واضح لذلك. . . . & $\bullet$ \\
\hline rr & 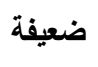 & 1.25 & 1.98 & فاتئ. المزاج و. & $\Lambda$ \\
\hline rr & ضعيفة & 1.26 & 1.90 & ير افقتي الشعور بالضجر حتى لو كان لاي ما يشغلني. & $v$ \\
\hline \multicolumn{2}{|c|}{ ضعيفة } & 1.21 & 2.24 & الارجة الكلية & \\
\hline
\end{tabular}


يتبين من الجدول (r) أن متوسط استجابات عينة الدراسة من طلاب المرحلة الثانوية

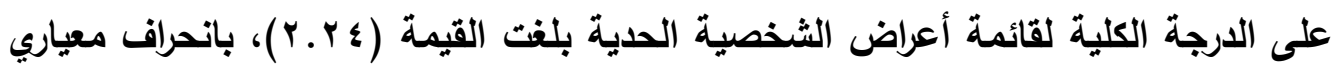

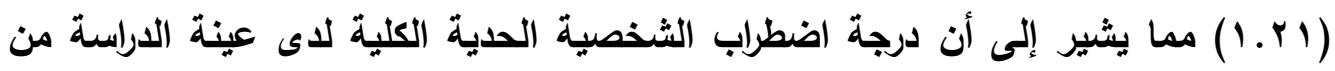
طلاب المرحلة الثانوية بمحافظة قلوة كانت (ضعيفة). ويرى الباحث أن النتيجة الحالية في مجملها تكثف عن كون الملاحظات التي اعتمدت التئل

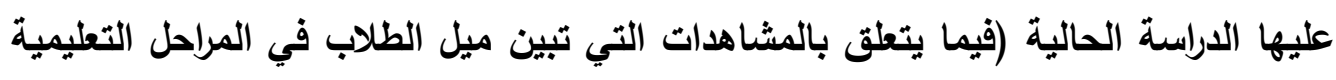

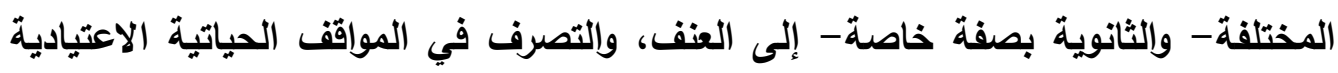

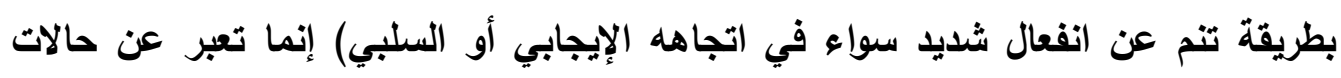

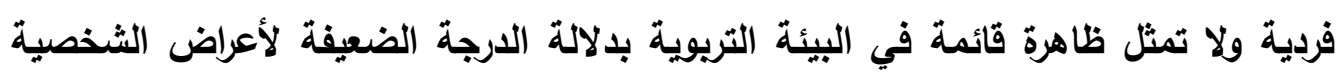
الحدية.

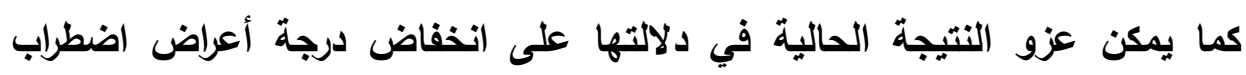

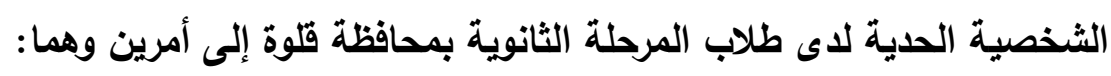

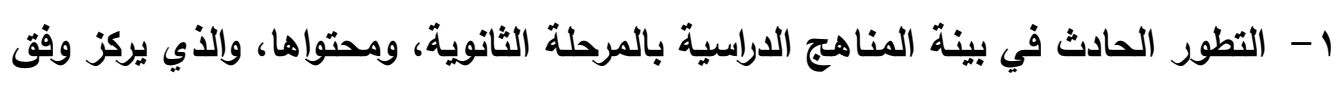

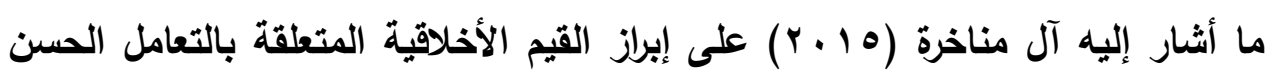

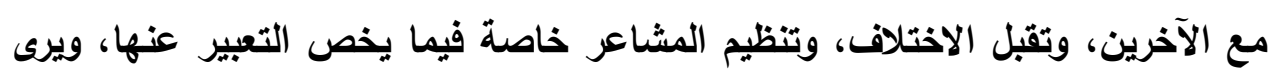

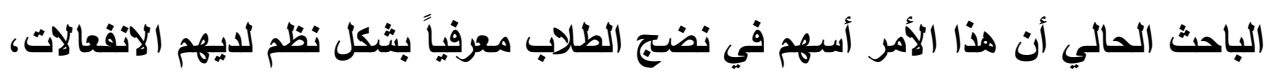

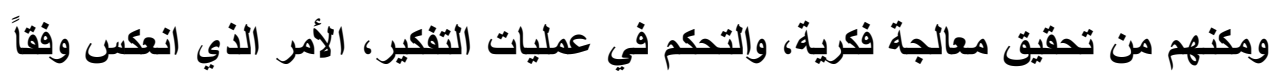

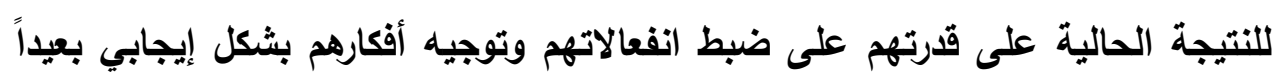
عن الحدة أو الطرفية الثديدة. r- محاولة الطلاب نحو الاندماج في المجتمع المحيط بهم، ورغبتهم الاخول في عالم الكبار

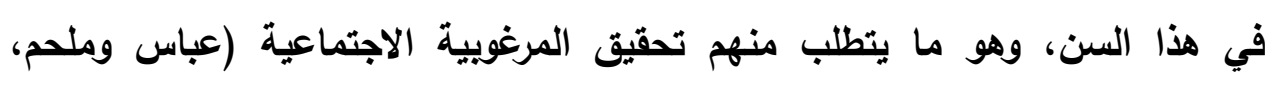

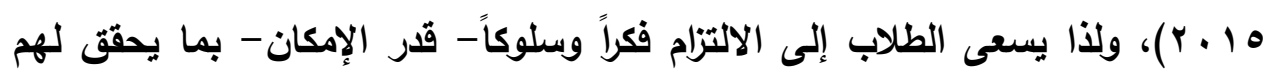

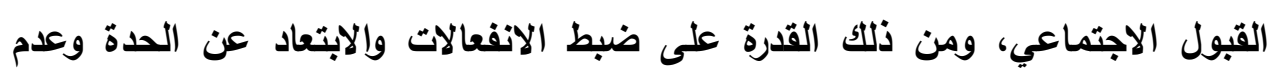

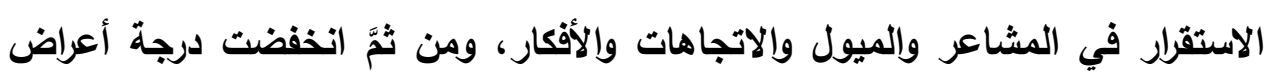
اضطراب الشخصية الحدية لايهم. 


\section{نتيجة السؤال الثالث ومناقشتها وتثسيرها :}

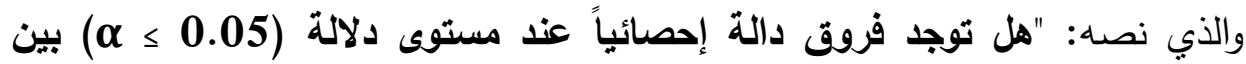
مرتفعي ومنخفضي الدوجماتية في درجة اضطراب الشخصية الحدية لاى طلاب المرحلة

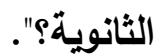

وللإجابة عن هذا السؤال، تم تحديد أعلى (rv. \%) من الدرجات على مقياس الجمود

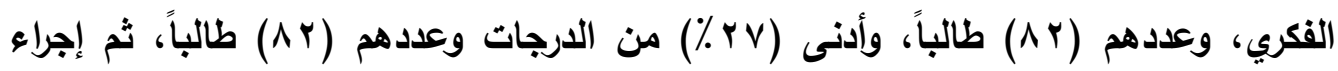
اختبار (ت) T.Test لعينتين مستقلتين لاختبار دلالة الفروق بين المجموعتين العليا والدنيا،

وذلك لأبعاد المقياس ودرجته الكلية، والجدول (؛ ) يبين نتائج هذا الإجراء. جدول (؛ ) نتائج اختبار (ت) لدالة الفروق بين مرتفعي ومنذفضي الجمود الفكري في اضطراب الثخصية الحدية الفئية

\begin{tabular}{|c|c|c|c|c|c|c|c|}
\hline \multirow{2}{*}{ الدلالة } & \multirow{2}{*}{ قيمة } & \multirow{2}{*}{ الدرجة } & \multicolumn{2}{|c|}{ منخفضو الجمود } & \multicolumn{2}{|c|}{ مرتفو الجمود } & \multirow{2}{*}{ المتغير } \\
\hline & & & $\varepsilon$ & م & $\varepsilon$ & p & \\
\hline$\cdot,+1$ & $v^{r} r$ & $17 r$ & Ir.or & $\varepsilon 7.1 \mathrm{r}$ & 18.9 & $0 \leqslant . \leqslant \wedge$ & الارجة الكلية لقائمة أعراض الثية العضية \\
\hline
\end{tabular}

يتبين من الجدول السابق وجود فروق ذات دلالة إحصائية عند مستوى دلالة ( 0.05) بين مرتفعي (المنغلقين) ومنخفضي (المنفتحين) الجمود الفكري في الدرجة الكلية لأعراض اضطراب الشخصية الحدية،. ويعزو الباحث النتيجة الحالية إلى ما سبقت الإثارة إليه- عند تناول نتيجة السؤال

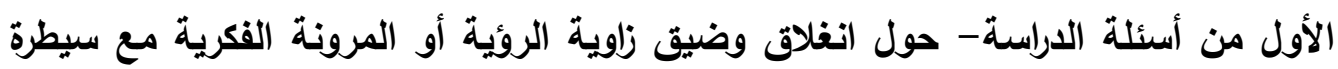

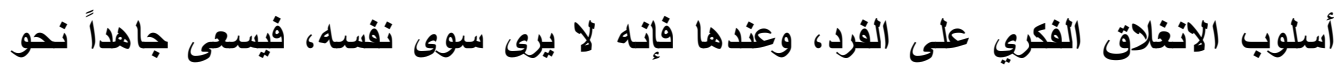

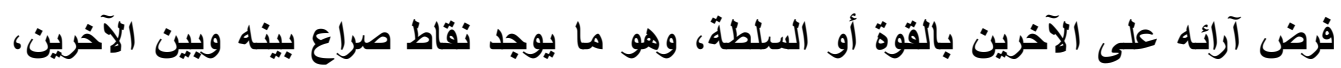

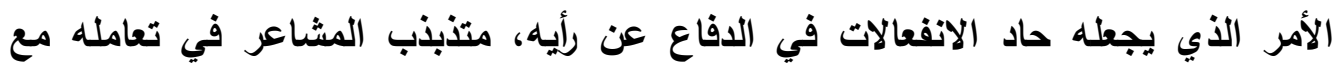
الآخرين، وهو ما يجعل شخصيته مضطربة، حيث ترتفع درجة الأعراض المرضية لايه. نتيجة السؤال الرابع ومنـاقشتها وتفسيرهـا. والذي نص على أنه: ما إمكانية التنبؤ باضطراب الشخصية الددية من خلال الجمود الفكري (الاوجماتية) لاى طلاب المرحلة الثانوية؟ 
وللإجابة عن هذا السؤال، تم استخدام تحليل الانحدار المتعدد بطريقة Enter لاستجابات عينة الدراسة على أداتيها: الجمود الفكري مقياس (الدرجة الكلية والأبعاد)،

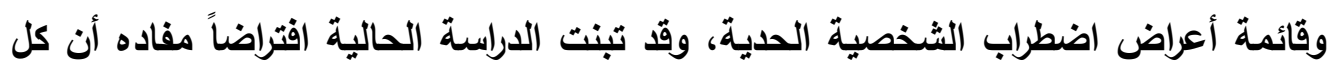
بعد من أبعاد الجمود الفكري يمثل في ذاته عاملاً مستقلاً يمكن أن يؤثثر في غيره من المتغير لابته

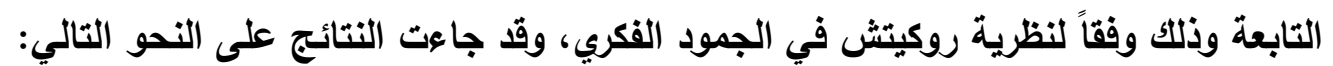

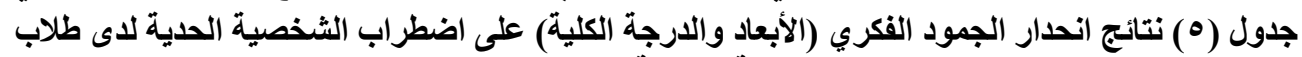

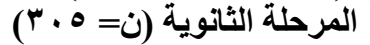

\begin{tabular}{|c|c|c|c|c|c|c|}
\hline الثابت & الاتحدار & قيمة (ت) & قلتباينة (ف) & $\begin{array}{c}\text { قيمة معامل } 1 \text { التحديد } \\
\text { (R2) }\end{array}$ & المتغير التابع & المتغير المستقل \\
\hline$r \leqslant . \wedge V$ & $\begin{array}{l}.97 \\
.97 \\
. .47 \\
.09\end{array}$ & $\begin{array}{l}* * 4.99 \\
* * \varepsilon .49 \\
* 4 . .9 \\
* * 4 . \wedge 9\end{array}$ & $* * 1 \wedge .+1$ & $\cdot .1$ & الأعزاضة الكلية & 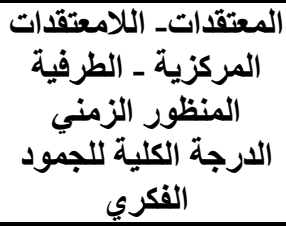 \\
\hline
\end{tabular}

تظهر النتائج إمكانية التنبؤ بالدرجة الكلية لأعراض اضطراب الشخصية الحدية من

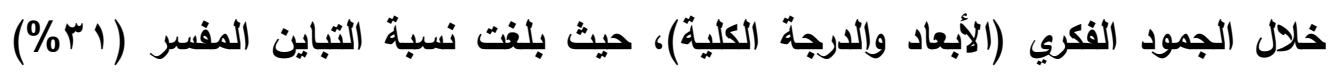

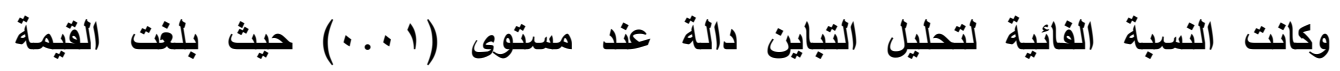
(11 (1 (1)، كما كان للجمود الفكري بأبعاده ودرجته الكلية تأثيرات موجبة ودالة إحصائياً

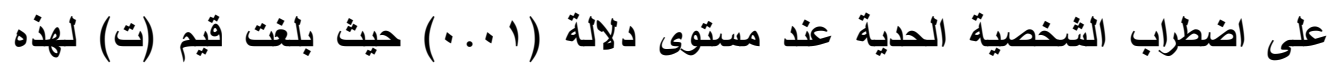

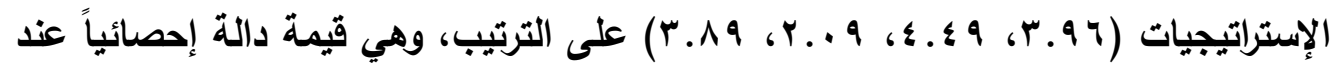

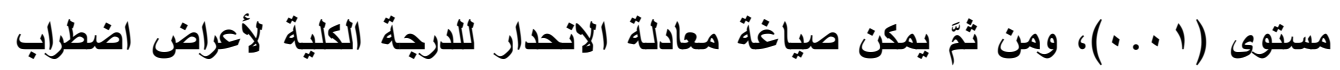

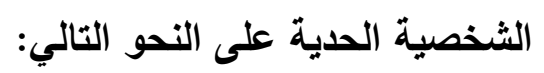

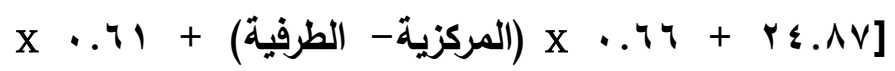

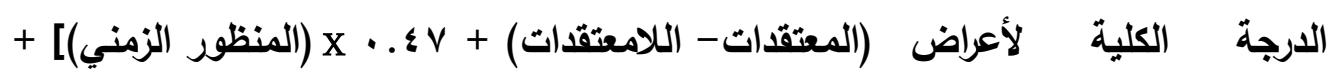

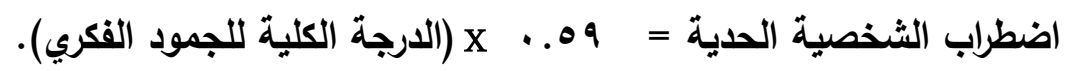

وتبين النتيجة الحالية أن أكثر أبعاد الجمود الفكري تأثيراً في تثكيل أعراض اضطراب

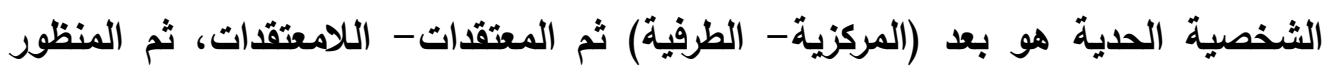


الزمني، وهو ما يتسق مع نتائج السؤال الرئيس للاراسة؛ والتي بينت أن أقوى أبعاد الجمود الفكري ارتباطاً باضطراب الثخصية العدية هو بعد المركزية- الطرفية.

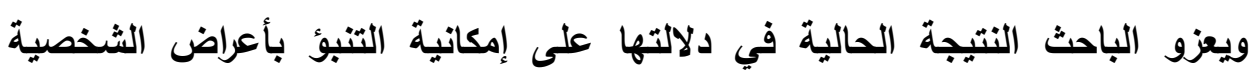

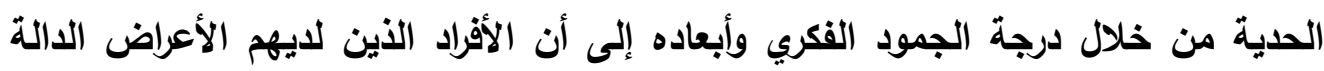

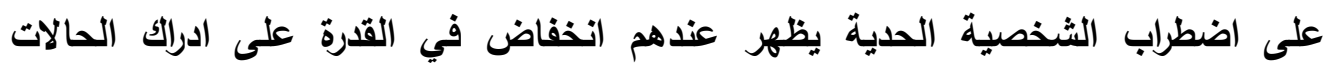

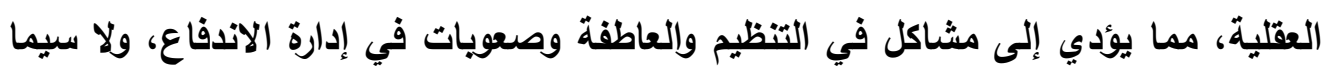

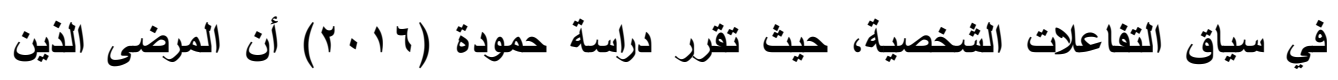

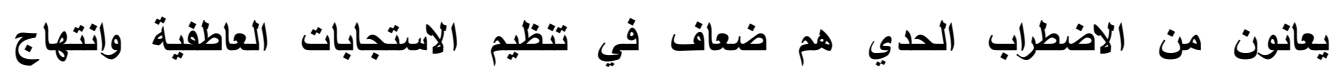

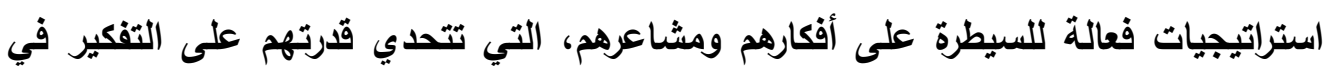

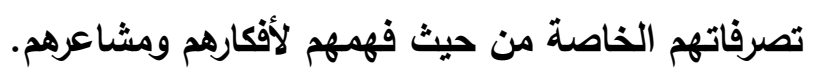

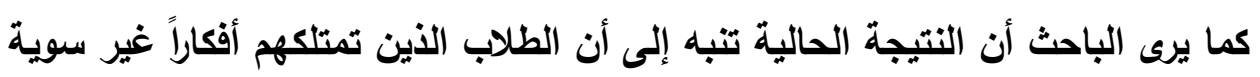

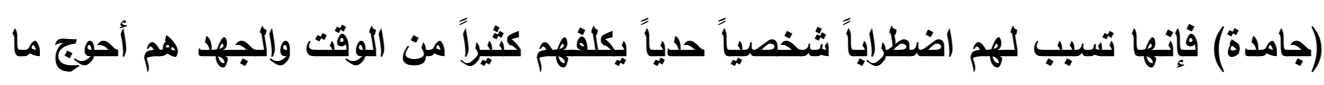

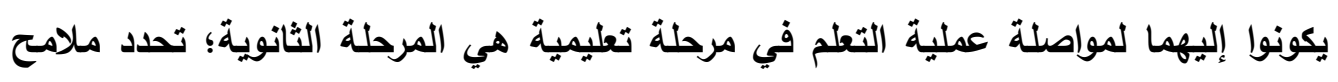

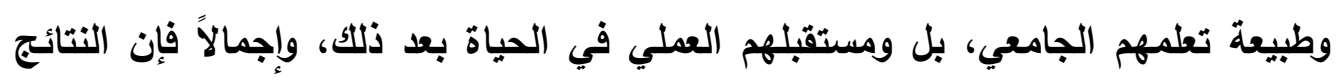

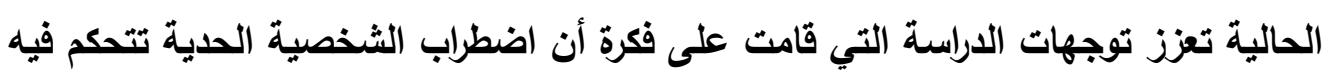

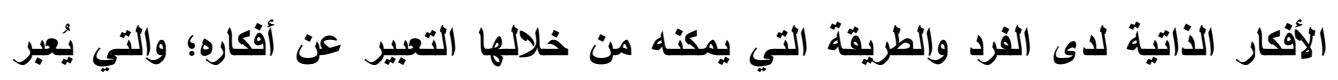

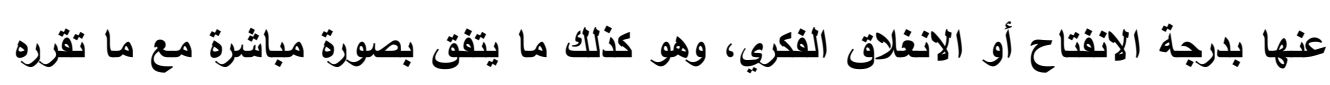

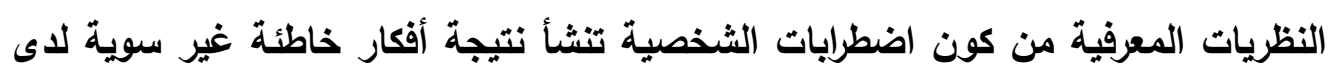
الفرد.

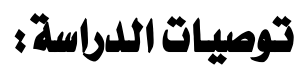

1- حث المؤسسات التعليمية ممثلة في المدارس الثانوية بإداراتها ومعلميها نحو تدعيم

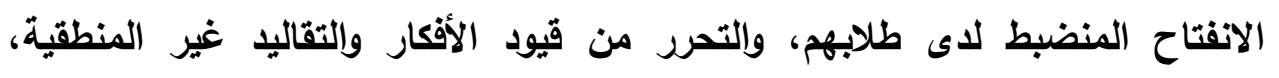

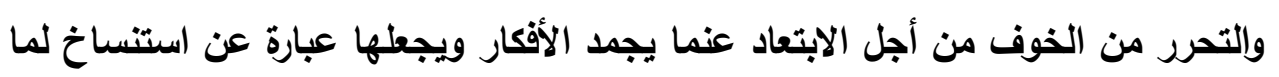


r- العمل على تحقيق التوعية اللينية بما يتناسب مع معطيات الحياة الاجتماعية والسياسية

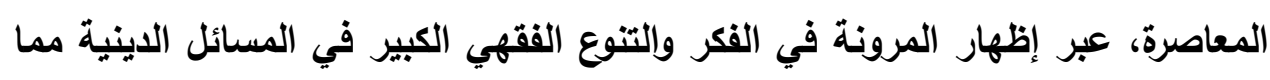
يسهم في إكساب الطلاب المرونة في التفكير، والبعد عن التعصب أو الجمود الفئن الفكري.

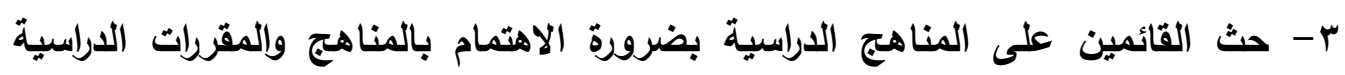

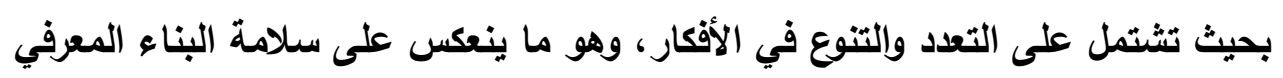
والانفعالي للطلاب، فتتميز شخصياتهم بالاستقرار والإيجابية. 


\section{مراجع الدراسة:}

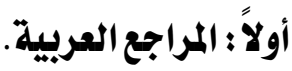

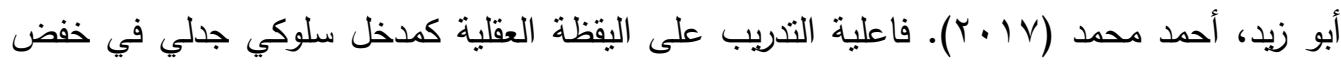

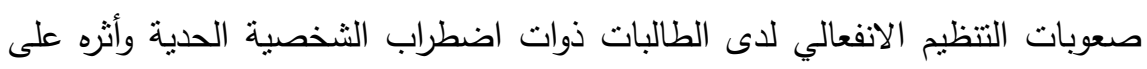

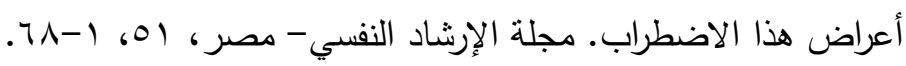

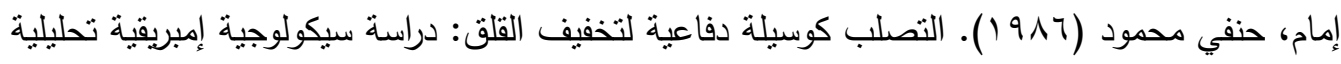

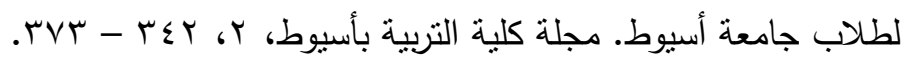

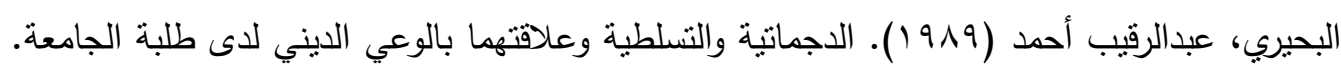
المؤتمر الخامس لعلم النفس، طنطا، مصر، الجمعية المصرية للاراسات النفسية وكلية

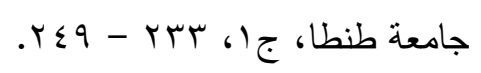

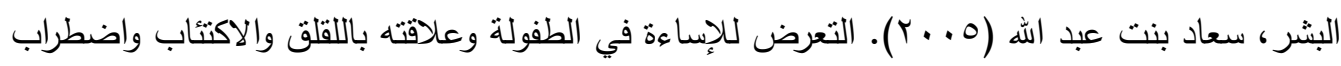

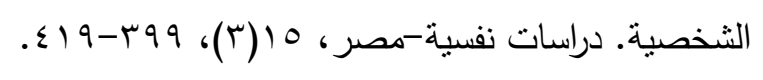

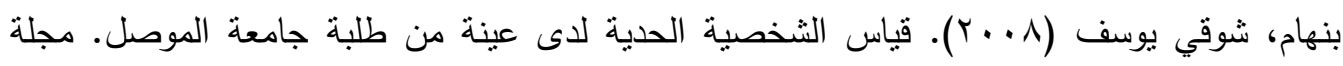

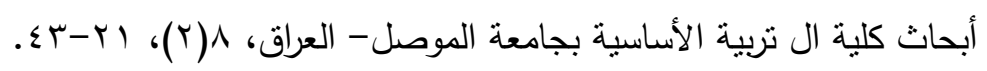

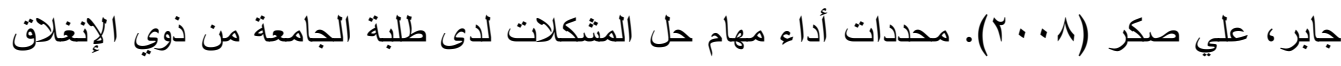

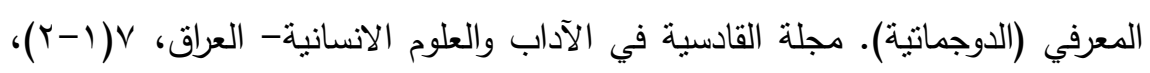

$$
\text { rOT-try }
$$

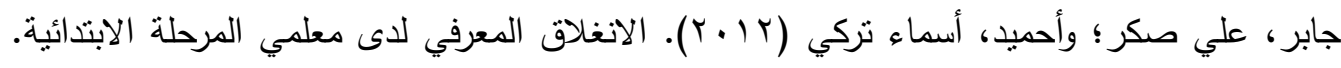

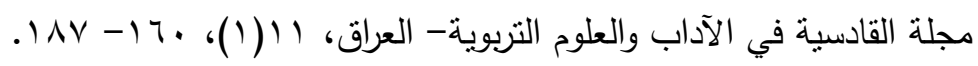

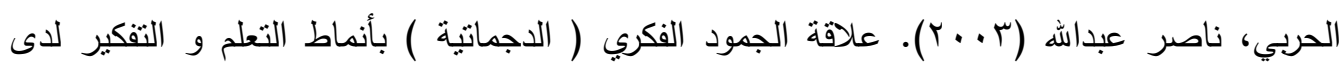

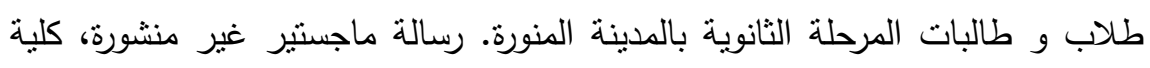

$$
\text { التربية، جامعة أم القرى، مكة المكرمة، المملكة العربية السعودية. }
$$

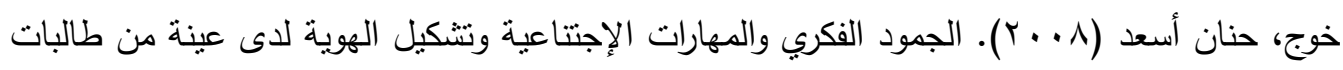

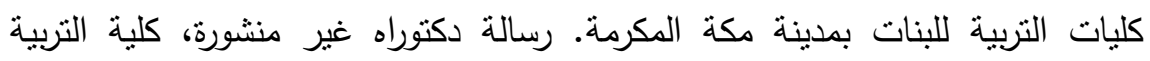

اللبنات، جامعة أم القرى، مكة المكرمة، المملكة العربية السعودية.

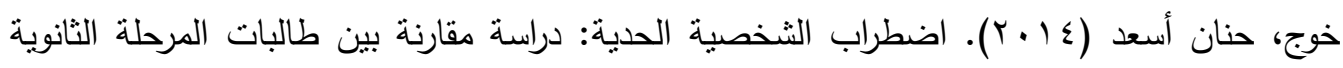

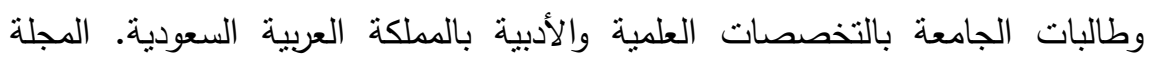

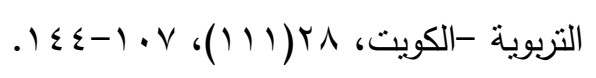


سيد، شيرين عبد القادر (T/ (Y). اليقظة العقلية كمتغير وسيط للعلاقة بين مظاهر اضطراب

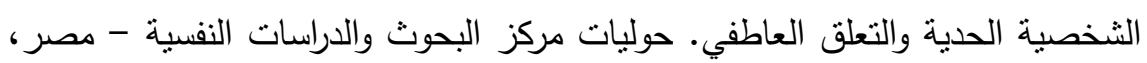

$$
.7 r-1 ،(9) \varepsilon
$$

سيلامي، نوربير (1 ( . (ץ). المعجم الموسوعي في علم النفس. ترجمة: وجيه أسعد، منشورات وزارة الثقافة، دمشق -سوريا.

الثحات، مجدي محمد (Y (Y). الفروق الفردية في ثقدير الذات وحل المشكلات بين مرتفعي ومنخفضي الدوجماتية لدى طلاب الجامعة. مجلة كلية التربية (جامعة بنها)، سب(ب 9)،

$$
\text { . rq }- \text { roo }
$$

شلبي، محمد أحمد والدسوقي، محمد إبراهيم وإبراهيم، زيزي السيد (ع ا • (). تشخيص الأمراض النفية للراشدين مستمدة من DSM4\& DSM-5. القاهرة: مكتبة الأنجلو المصرية. عباس، مدحت ألطاف وشوبخ، هناء أحمد محمد (9 . . ( ). صورة الجسم والشخصية البينية (الحدية) وعلاقتهما ببعض الاضطرابات السيكوسوماتية لدى طلاب الجامعة. مجلة كلية التربية

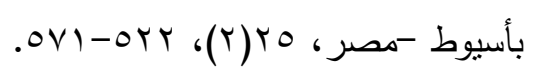

عليان، وفاء مصطفى (ع ( • r). الجمود الفكري وقوة الأنا وعلاقتهما بجودة الحياة لدى طلبة الجامعات بلات بمحافظات غزة. رسالة ماجستير غير منشورة. كلية التربية، جامعة الأزهر، غزة،

$$
\text { فلسطين. }
$$

فوزي، طارق محمد وقاعود، محمود عبد العزيز ( ع... (ض). اضطراب الثخصية التجنبية وعلاقته بالحيز الشخصي لدى عينة من طلاب الجامعة. مؤتمر قسم علم النفس الأول جامعة

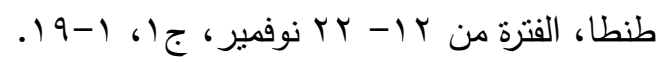

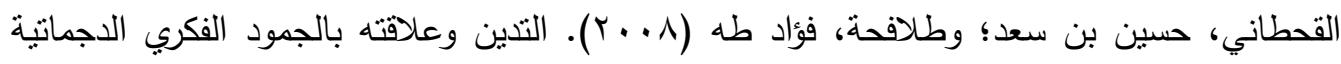
دراسة ميدانية على طلبة كلية المعلمين لمدينة تبوك. مؤنة للبحوث والدراسات، سلسلة

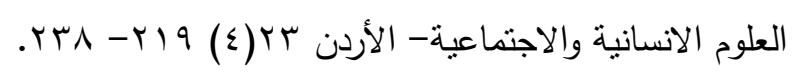

القحطاني، محمد علي (1 . . r). الدوجماتية بين الماهية وإمكانية القياس لدى الاسترهابيين. رسالة دكتوراه غير منشورة، قسم العلوم الإدارية، جامعة نايف العربية للعلوم الامنية، الرياض،

المملكة العربية السعودية.

لمبارك، سمية (9 . . ب). أسلوب الدوجماتية لاى الطلبة الجامعيين. رسالة ماجستير غير منشورة، كلية العلوم الإنسانية والاجتماعية والعلوم الإسلامية، جامعة الحاج الخضر ، الجزائر . 


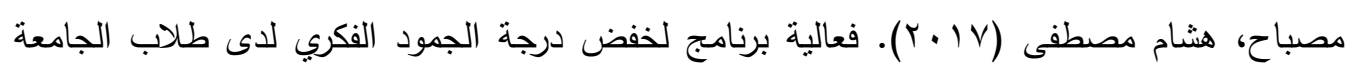

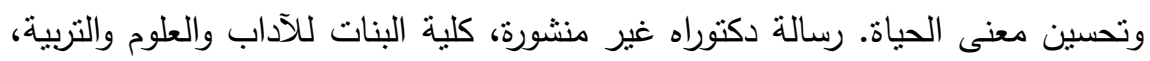

$$
\text { جامعة عين شمس. }
$$

ثانياً : المراجع الأجنبية.

Brown, A. (2007). A Cognitive Approach to Dogmatism: An Investigation into the Relationship of Verbal Working Memory to Dogmatism. Journal of Research in Personality, 41(4): 946-952.

Ewing ,D. (2010). The relations among anomie,dogmatism, and selected personal social factors in asocial addescent boys. Journal of Social Issues, 27(4), 235-251.

Ferrando, J., Fabia, M.\& Urbano, L. (2016). Acquiescence and Dogmatism: Impact and relations across two different item formats. Personality and Individual Differences, 99(3), 331-335.

Finley, A.; Buffett- Jerrott, S.; Stewart, S. H.; \&. Millington, D. (2002). Effects of midazolam on prcoperative anxiety in children. Canadian Journal of Anesthesia, N(43), 88-109.

Gurney, D., McKeown, S., Churchyard, J.\& Howlett, N. (2013). Believe it or not: Exploring the relationship between dogmatism and openness within non-religious samples. Personality and Individual Differences, 55(8), 936-940.

Moore, K., Tull, M.\& Gratz, K. (2017). Borderline personality disorder symptoms and criminal justice system involvement: The roles of emotion-driven difficulties controlling impulsive behaviors and physical Aggression. Comprehensive Psychiatry, 76, 26-35.

Samaie, M. \& Mansour, M. (2015). The Relationship Between Dogmatism and Emotional Intelligence with Psychological ${ }^{\wedge}$ Vell - Being. International Journal of Fundamental Psychology and Social Sciences (IJFPSS), 5(1): 7-11.

White - Ajmani, M. \& Burski, K. (2011). What Lies Beneath: Dogmatism, Intolerance, and Political Self - Identification. Individual Differences Research, 9(3): 153-164 